\title{
Association between dietary sodium, potassium intake and lung cancer risk: evidence from the prostate, lung, colorectal and ovarian cancer screening trial and the Women's Health Initiative
}

\author{
Dongfang You ${ }^{1 \#}$, Mingzhi Zhang ${ }^{1 \#}$, Wenjing $\mathrm{He}^{2}$, Danhua Wang ${ }^{3}$, Yang Yu ${ }^{1}$, Zhaolei Yu ${ }^{1}$, Theis Lange ${ }^{4}$, \\ Sheng Yang ${ }^{1}$, Yongyue Wei ${ }^{1,5}$, Hongxia $\mathrm{Ma}^{6,7,8}$, Zhibin $\mathrm{Hu}^{6,7,8}$, Hongbing Shen ${ }^{6,8}$, Feng Chen ${ }^{1,5}$, Yang Zhao ${ }^{1,5,7}$ \\ ${ }^{1}$ Department of Biostatistics, School of Public Health, Nanjing Medical University, Nanjing, China; ${ }^{2}$ Zhengzhou Central Hospital Affiliated \\ Zhengzhou University, Zhengzhou, China; ${ }^{3}$ Department of Public Health and Preventive Medicine, Kangda College of Nanjing Medical University, \\ Lianyungang, China; ${ }^{4}$ Section of Biostatistics, Department of Public Health, Faculty of Health and Medical Sciences, University of Copenhagen, \\ Øster Farimagsgade 5, 1353, Copenhagen, Denmark; ${ }^{5}$ Center of Big Data of Nanjing Medical University, Nanjing, China; ${ }^{6}$ Department of \\ Epidemiology, School of Public Health, Nanjing Medical University, Nanjing, China; ${ }^{7}$ Jiangsu Key Lab of Cancer Biomarkers, Prevention and \\ Treatment, Collaborative Innovation Center for Cancer Personalized Medicine, Nanjing Medical University, Nanjing, China; ${ }^{8}$ China International \\ Cooperation Center (CICC) for Environment and Human Health, Nanjing Medical University, Nanjing, China \\ Contributions: (I) Conception and design: T Lange, S Yang, Y Wei, H Ma, Z Hu, H Shen, F Chen, Y Zhao; (II) Administrative support: F Chen, Y \\ Zhao; (III) Provision of study materials or patients: F Chen, Y Zhao; (IV) Collection and assembly of data: D You, M Zhang, W He, D Wang, Y Yu, \\ Z Yu; (V) Data analysis and interpretation: D You, M Zhang; (VI) Manuscript writing: All authors; (VII) Final approval of manuscript: All authors. \\ \#These authors contributed equally to this work. \\ Correspondence to: Yang Zhao; Feng Chen. Department of Biostatistics, School of Public Health, Nanjing Medical University, Nanjing, China. Email: \\ yzhao@njmu.edu.cn; fengchen@njmu.edu.cn.
}

Background Epidemiological studies have reported that dietary mineral intake plays an important role on lung cancer risk, but the association of sodium, potassium intake is still unclear.

Methods: We determined the association between dietary sodium, potassium intake and lung cancer risk based on the Prostate, Lung, Colorectal and Ovarian (PLCO) cancer screening trial and the Women's Health Initiative (WHI). Totally 165,409 participants who completed the baseline questionnaire (BQ) and diet history questionnaire (DHQ) were included into the analytical dataset, including 92,984 (44,959 men and 48,025 women) from the PLCO trial and 72,425 (women only) from the WHI cohort. Multivariable Cox proportional hazards regression was used to calculate hazard ratios (HRs) and 95\% confidence intervals (CIs) of incident lung cancer associated with dietary potassium and sodium intake. The dose-response relationship was also described using the spline smoothed curve after adjusting covariates.

Results: After the median follow-up of 8.55 and 18.56 years, 1,278 and 1,631 new cases of lung cancer were identified in the PLCO trial and WHI cohort, respectively. Intake of sodium was significantly associated with the incidence of lung cancer in the PLCO trial after multivariate adjustment for men (HR: 1.19, 95\% CI: $1.05-1.35$; P for linear trend =0.044). There was a suggestion that lung cancer risk had a quadratic curve correlation with the increase of potassium intake for women (third vs. lowest quintile: HR: 0.72, 95\% CI: 0.54-0.96; P for quadratic trend =0.042). The similar results showing an inverse association between potassium intake and lung cancer risk were also observed in the WHI cohort for women (highest vs. lowest quintile: HR: 0.82, 95\% CI: 0.70-0.97; P for linear trend =0.009).

Conclusions: Appropriate intake of potassium has a protective effect against lung cancer, while high consumption of sodium is associated with an increased risk of lung cancer.

Keywords: Lung cancer; sodium; potassium; cancer screening; Women's Health Initiative

Submitted Jul 19, 2020. Accepted for publication Dec 02, 2020.

doi: $10.21037 /$ tlcr-20-870

View this article at: http://dx.doi.org/10.21037/tlcr-20-870 


\section{Introduction}

Lung cancer is the most frequent malignant cancer and the leading cause of cancer mortality worldwide (1), with 2.1 million new cases accounting for $11.6 \%$ of the total new cancer cases and 1.8 million deaths accounting for $18.4 \%$ of the total cancer deaths predicted in 2018 (2). Previous studies have identified the risk factors contributing to the occurrence of lung cancer, such as cigarette smoking, gender and air pollution (3).

Recently, emerging evidence has suggested that intake of dietary minerals may have an impact on the incidence of lung cancer. It was found that both a higher zinc and iron intake was associated with a reduced risk of lung cancer $(4,5)$. Similar protective effects of zinc were also reported in three large case-control studies. For the association between calcium intake and lung cancer risk, however, the findings were inconsistent. An increased risk of lung cancer risk on calcium intake was identified in a case-control study by Zhou et al., while an inverse association was found in the National Cancer Institute (NIH)-American Association of Retired Persons Diet and Health study (6). Moreover, several studies also showed that both copper and selenium may decrease the risk of lung cancer (7).

Potassium and sodium are two of the necessary trace elements in the human body, which are mainly derived from diet. Previously, several studies reported that high intake of potassium was negatively related to the occurrence of colorectal cancer, and high sodium consumption could increase the risk of renal cell cancer, colorectal cancer, and gastric cancer (8-11). However, there are few studies on the relationship between potassium, sodium intake and the risk of lung cancer.

In the present study, we aimed to evaluate whether dietary potassium, sodium intake was associated with lung cancer risk using the data from both the Prostate, Lung, Colorectal, and Ovarian (PLCO) cancer screening trial and the observational study of the Women's Health Initiative (WHI).

The authors present the following article in accordance with the STROBE reporting checklist (available at http:// dx.doi.org/10.21037/tlcr-20-870).

\section{Methods}

\section{Study population}

Totally 111,383 out of 154,897 participants in the PLCO cancer screening trial conducted at 10 study centers and sponsored by the National Cancer Institute (NCI) which was carried out to evaluate whether selected screening methods could reduce the mortality from prostate, lung, colorectal, and ovarian cancer completed the baseline questionnaire (BQ) and diet history questionnaire (DHQ) (12). After excluding 7 deaths prior to completion of the DHQ, 16 cases without the completion date of the DHQ, 3,039 cases skipping $\geq 8$ food frequency questions and 2,179 cases of extreme energy intake, there were 106,435 participants completing the eligible DHQ. Finally 92,984 cases were included into the analytical dataset after excluding 4,354 deaths or cancer cases diagnosed prior to the date of DHQ and 9,097 cases of missing necessary covariates (alcohol intake, smoking status, pack-years of smoking, body mass index (BMI), education, diabetes history, and family history of lung cancer) (13). The flow diagram describing the population selection process was listed in Figure $1 \mathrm{~A}$.

A total of 93,676 postmenopausal females aged 50-79 years were enrolled in the observational study (a sub-cohort) of the WHI which was a long-term national health study sponsored by the National Heart, Lung, and Blood Institute (NHLBI), with the purpose of exploring new risk indicators and biomarkers of morbidity and mortality in postmenopausal females (14). A similar selection procedure was performed in the WHI cohort (Figure 1B). Finally, 165,409 participants were included into the overall analytical dataset, including 92,984 (44,959 males and 48,025 females) from the PLCO trial and 72,425 (females only) from the WHI cohort.

The studies were approved by the corresponding institutional review boards and all the participants provided written informed consent $(12,15)$.

\section{Data collection}

In the PLCO trial, all the participants completed a selfadministered baseline questionnaire with demographic information, such as age, gender, race, education, family history of cancer, smoking history, medical history, and past screenings. BMI was computed as weight $(\mathrm{kg}) /$ height $(\mathrm{m})^{2}$. Dietary data were collected through Dietary History Questionnaire (DHQ) which included 156 questions about the consumption frequencies of various foods, drinks, supplements, and other items. Furthermore, the daily intake of nutrients including potassium and sodium was derived from the frequency and portion-size responses to the food frequency questionnaire (FFQ), in which the 

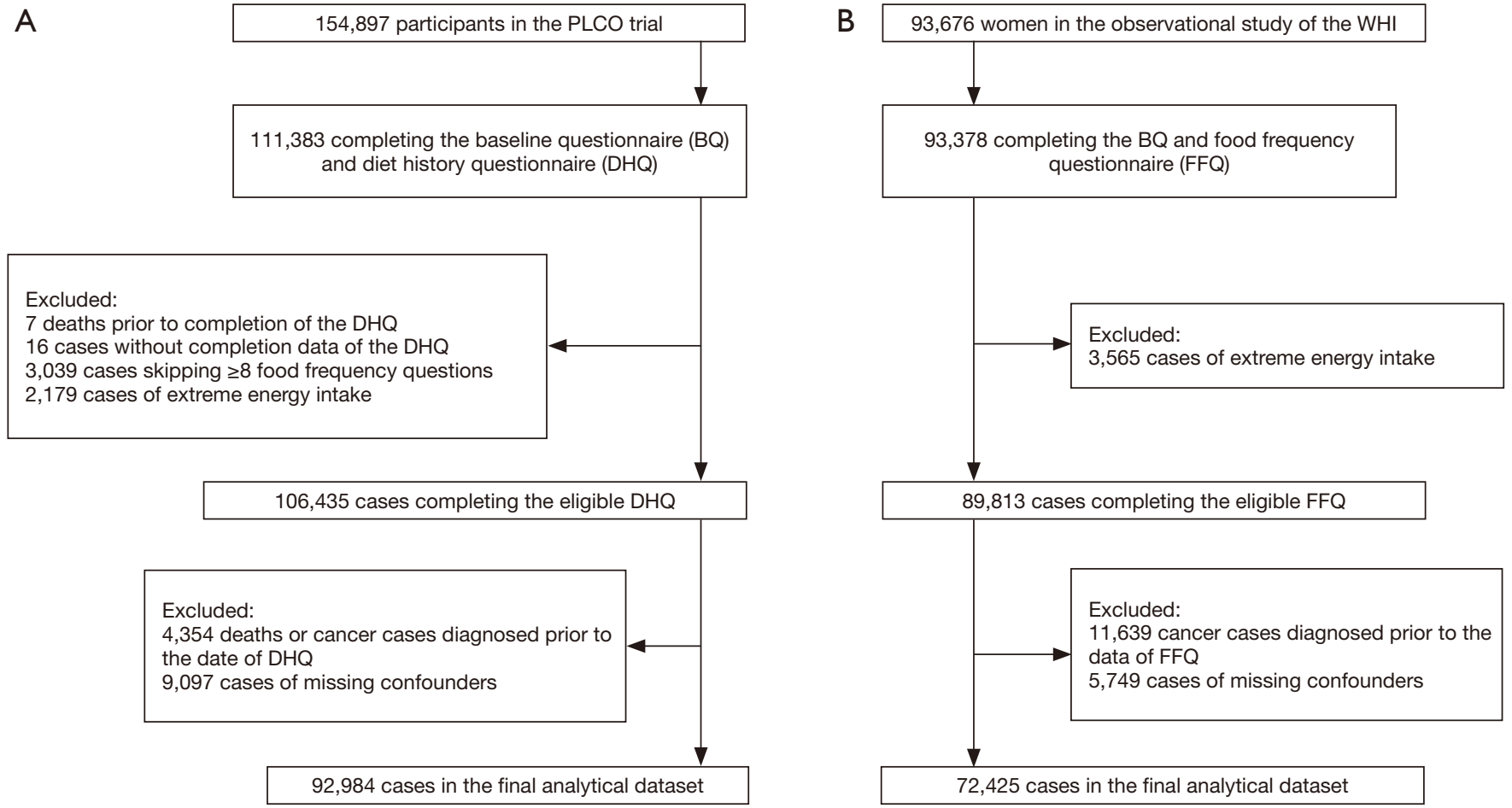

Figure 1 The flow diagram describing the population selection process: the PLCO trial (A) and the observational study of the WHI (B).

relevant nutrient values were multiplied by the frequency and summed across. The nutrient composition databases were calculated by DietCalc software, in conjunction with a nutrient database based on the national dietary data [USDA's 1994-96 Continuing Survey of Food Intakes by Individuals (CSFII), available from the USDA Food Survey Research Group, or the Nutrition Data Systems for Research (NDS-R) from the University of Minnesota] (16).

The demographic information was collected for every participant in the WHI cohort. Dietary data were collected through FFQ with 145 items which consisted of three basic components: a food list, a frequency response section for subjects to report how often each food was eaten and portion-size information. Additionally, the nutrient database used in the FFQ analysis software was based on the University of Minnesota's Nutrition Coordinating Center's (UM-NCC) nutrient database.

\section{Confirmation of lung cancer}

In both cohorts, the reports of lung cancer were collected through various methods including but not limited to the annual questionnaires which were mailed to all participants to determine the incidence of lung cancer and the diagnostic data within one year, family reports and death certificates. All the reports of lung cancer diagnosis were followed up and confirmed through abstraction of medical records $(12,15)$.

\section{Statistical analysis}

When analyzing the association between dietary sodium, potassium intake and lung cancer risk, the mineral intake was firstly energy-adjusted by the residual method (17). For the primary analysis, participants were divided into quintiles of average intake of sodium or potassium in each cohort. The associations between mineral intake and risk of incidence were analyzed separately for different genders as the overall dietary mineral intake were significantly different between male and female. In addition, a pooled analysis was performed on all the females from the two cohorts.

Multivariable Cox proportional hazards regression was used to calculate the hazard ratios (HR) and its $95 \%$ confidence intervals (CI) for incident lung cancer associated with dietary potassium and sodium intake. Follow-up time was defined as the interval between the recruitment date to that of lung cancer diagnosis or withdrawal (death or the end of follow-up). Covariates adjusted in the Cox model 
included age, gender, BMI at baseline, energy from diet, education level (low: high school or below, intermediate: post high school or junior college, high: college or above), alcohol consumption, smoking status (never smokers, former smokers $<20$ pack-years, former smokers $\geq 20$ packyears, current smokers $<20$ pack-years, current smokers $\geq 20$ pack-years), previous history of diabetes mellitus, and family history of lung cancer. The family history of cancer, but not lung cancer, was adjusted in the multivariable regression model for the WHI cohort because the information of lung cancer was not collected. When testing for trend across quintiles of mineral intake, median values were assigned to denote the corresponding quintiles. Furthermore, the doseresponse relationship between dietary sodium or potassium intake and the lung cancer risk was described in a Cox proportional hazard model using the spline smoothed curve after adjusting covariates mentioned previously (18).

We further performed extensive sensitivity analysis to evaluate the robustness of our findings. Some studies suggested that yogurt rich in potassium was inversely associated with lung cancer risk after adjustment for other risk factors (19). In our study, it was found the average yogurt intake of females was twice as much as that of males in the PLCO trial. Besides, the ethnic differences may also have an impact on the results. Therefore, sensitivity analyses were conducted by including yogurt intake or race in the multivariable model. In order to reduce the bias due to measurement errors, we applied the "calibration" equations, details of the study have been described in (20), to FFQ data to estimate calibrated intake and performed the same Cox proportional hazards regression as another sensitivity analysis for the WHI cohort.

Additional analysis was performed after excluding the participants who were diagnosed with cancers other than lung cancer. We also evaluate the association between potassium and sodium intake and lung cancer risk at the different stratum determined by smoking status and classification [non-small cell lung cancer (NSCLC) or small cell lung cancer (SCLC)].

All statistical analyses were performed using R software (version 3.5.1). A value of $\mathrm{P} \leq 0.05$ was considered statistically significant.

\section{Ethical approval}

The study was conducted in accordance with the Declaration of Helsinki (as revised in 2013). The usage of the lung cancer database in the PLCO and WHI studies was authorized by the ethics committees of the data providers and Nanjing Medical University.

\section{Results}

\section{Description of the study population}

Table 1 showed the baseline characteristics of lung cancer cases and controls in the PLCO trial and WHI cohort. After the median follow-up of 8.55 and 18.56 years, 1,278 and 1,631 new cases of lung cancer were identified in the PLCO trial and WHI cohort, respectively. Significant differences were exhibited between confirmed and nonconfirmed lung cancer cases in the PLCO trial and WHI cohort regarding age, BMI, educational level, smoking status, alcohol consumption and family history of cancer $(\mathrm{P}<0.05)$. The cases in the PLCO trial were more likely to be male $(\mathrm{P}<0.001)$ and had a higher total energy intake $(\mathrm{P}=0.005)$, while those in the WHI cohort had a lower intake of potassium $(\mathrm{P}=0.001)$. Baseline characteristics of the study population according to quintiles of mineral intake and the correlation coefficients between minerals and dietary food sources were described in Tables S1-S3. It is important to notice that the distributions of mineral intake were significantly different between male and female. Males in the PLCO cohorts had higher sodium and potassium intakes than females in both the PLCO and WHI cohorts $(\mathrm{P}<0.001)$, which highlight the importance of making gender-specific analysis on the lung cancer risk on dietary mineral intakes (Figure S1).

\section{Gender-specific association between mineral intake and risk of lung cancer}

As shown in Table 2, higher intake of potassium was associated with a decreased risk of lung cancer in the WHI cohort. Compared with the subgroup with the lowest potassium intake (median intake $1,914 \mathrm{mg} / \mathrm{day}$ ), the HRs and $95 \%$ CIs for subgroups with the second highest (median intake $2,935 \mathrm{mg} /$ day) and highest intake (median intake $3,450 \mathrm{mg} /$ day) were $0.85(0.73,0.99)$ and $0.82(0.70,0.97)$. We also identified a significant linear trend between potassium intake and lung cancer risk $(\mathrm{P}=0.009)$. Furthermore, the spline smoothed curve analysis demonstrated a significant dose-response association between potassium intake and risk of incident lung cancer (Figure 2A). For females in the PLCO trial, although not significant, higher potassium intake groups 
Table 1 Baseline characteristics of lung cancer cases and controls in the PLCO trial and the WHI cohort

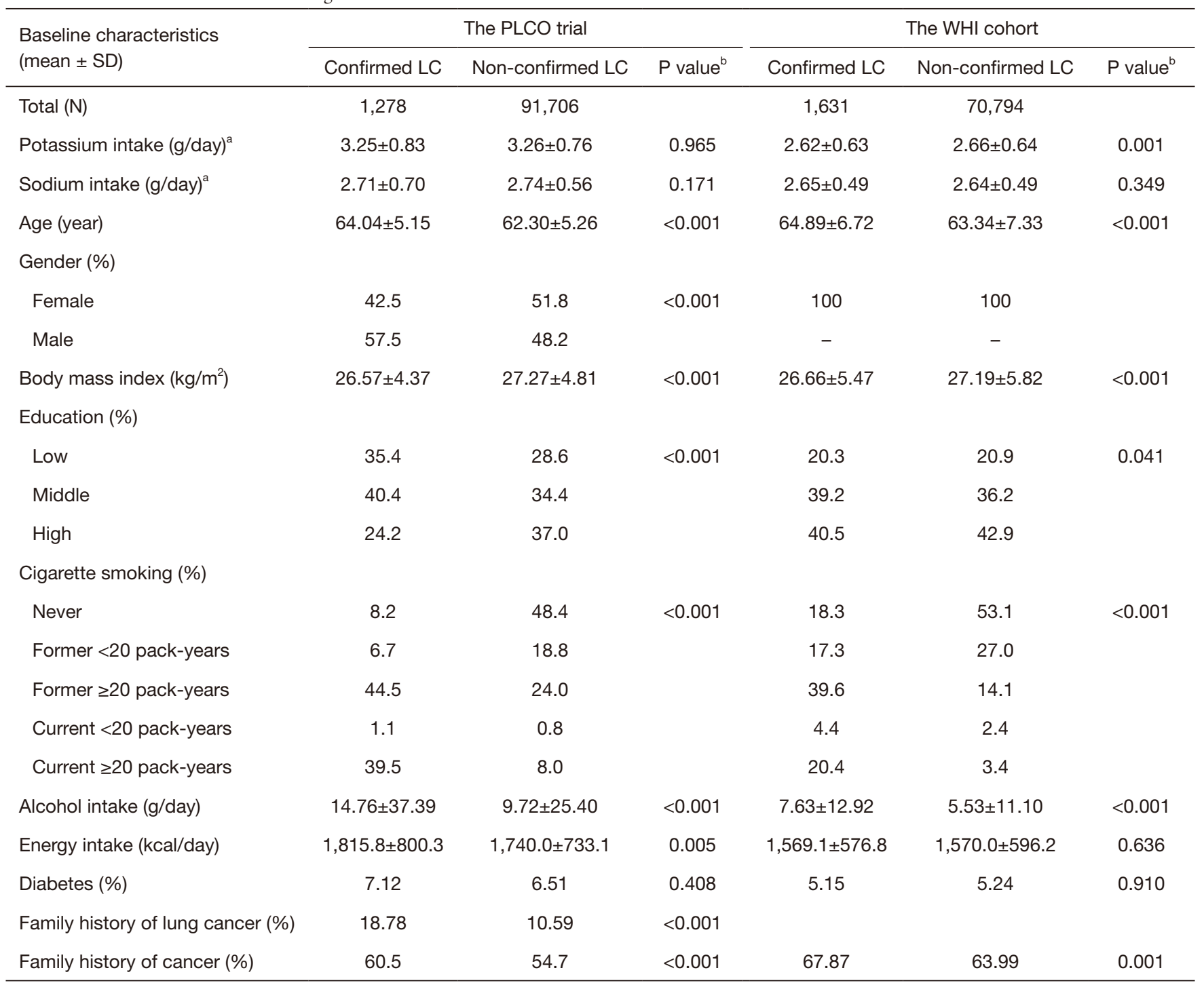

$\mathrm{SD}$, standard deviation; LC, lung cancer. ${ }^{\text {a }}$, intake was energy-adjusted. ${ }^{\mathrm{b}}, \mathrm{P}$ value for difference was tested using Wilcox rank sum test (continuous) or Chi-square test (categorical).

showed protective effects against lung cancer. As the spline smoothed curve shown in Figure 2B, the trend of HRs with potassium intake were in quadratic, subgroup with median potassium intake was associated with $26 \%$ reduction in the risk of lung cancer (compared with the lowest: HR: 0.72, 95\% CI: 0.54-0.96). This was verified by fitting a quadratic regression with a squared term of potassium intake ( $\mathrm{P}$ for quadratic trend $=0.04)$. Similar trend was also observed in the pooled analysis (Figure 2C). However, the association was not significant for potassium intake in males (HR: 1.06, 95\% CI: 0.97-1.17, Figure 2D).

As for sodium intake, higher sodium intake was significantly associated with increased lung cancer risk for males in the PLCO trial (HR: 1.19, 95\% CI: 1.05-1.35, P for linear trend $=0.044)$. For females, we observed a linear trend for sodium intake against lung cancer in the PLCO (P for trend $=0.022$ ), while only a suggestive but not significant association in the WHI cohort (HR: 1.10, 95\% CI: 0.991.21; $\mathrm{P}$ for trend $=0.080$ ). Corresponding spline smoothed curves were shown in Figure 3.

\section{Pooled analysis on females in both cohorts}

A pooled analysis was performed by combining females 
Table 2 Gender-specific hazard ratios and 95\% confidence intervals of lung cancer based on categories of dietary mineral intake

\begin{tabular}{|c|c|c|c|c|c|c|}
\hline & Continuous & Quintile 1 & Quintile 2 & Quintile 3 & Quintile 4 & Quintile 5 \\
\hline \multicolumn{7}{|l|}{ WHI (female only) } \\
\hline Dietary intake ${ }^{a}$ & $2,619.5$ & $<2,153.6$ & 2,153.6-2,473.8 & 2,473.8-2,768.2 & $2,768.2-3,139.5$ & $\geq 3,139.5$ \\
\hline Cases/person-years & $1,631 / 1,123,470$ & $368 / 207,916$ & $336 / 220,409$ & $332 / 228,708$ & $304 / 231,972$ & $291 / 234,465$ \\
\hline$P$ value & 0.124 & \multicolumn{5}{|c|}{$P_{\text {trend }}{ }^{c}=0.009$} \\
\hline \multicolumn{7}{|l|}{ Female in the PLCO } \\
\hline Dietary intake ${ }^{a}$ & $2,943.8$ & $<2,463.4$ & $2,463.4-2,797.0$ & 2,797.0-3,096.8 & $3,096.8-3,487.7$ & $\geq 3,487.7$ \\
\hline Cases/person-years & $543 / 390,992$ & $123 / 77,876$ & $106 / 77,994$ & $87 / 77,975$ & $103 / 78,589$ & $124 / 78,558$ \\
\hline \multicolumn{7}{|l|}{ Male in the PLCO } \\
\hline Dietary intake ${ }^{a}$ & $3,489.9$ & $<2,935.9$ & 2,935.9-3,319.7 & $3,319.7-3,670.0$ & $3,670.0-4,142.0$ & $\geq 4,142.0$ \\
\hline Cases/person-years & $735 / 343,836$ & $152 / 68,795$ & $127 / 68,496$ & $145 / 68,642$ & 159/68,905 & $152 / 68,998$ \\
\hline Multivariable model $\mathrm{HR}^{\mathrm{b}}$ & $1.06(0.97,1.17)$ & 1.00 & $0.93(0.73,1.18)$ & $1.05(0.83,1.33)$ & $1.12(0.89,1.41)$ & $1.05(0.83,1.33)$ \\
\hline$P$ value & 0.188 & \multicolumn{5}{|c|}{$P_{\text {trend }}{ }^{c}=0.348$} \\
\hline \multicolumn{7}{|l|}{ Sodium } \\
\hline \multicolumn{7}{|l|}{ WHI (female only) } \\
\hline Dietary intake ${ }^{a}$ & $2,620.2$ & $<2,291.5$ & $2,291.5-2,522.5$ & $2,522.5-2,722.4$ & $2,722.4-2,980.3$ & $\geq 2,980.3$ \\
\hline Cases/person-years & $543 / 390,992$ & $143 / 77,508$ & $101 / 78,109$ & $106 / 78,154$ & $100 / 78,802$ & $93 / 78,418$ \\
\hline Multivariable model $\mathrm{HR}^{\mathrm{b}}$ & $0.83(0.68,1.01)$ & 1.00 & $0.80(0.62,1.04)$ & $0.91(0.70,1.18)$ & $0.82(0.63,1.07)$ & $0.71(0.54,0.93)$ \\
\hline$P$ value & 0.057 & \multicolumn{5}{|c|}{$P_{\text {trend }}{ }^{c}=0.022$} \\
\hline \multicolumn{7}{|l|}{ Male in the PLCO } \\
\hline Dietary intake ${ }^{a}$ & $3,108.9$ & $<2,732.1$ & 2,732.1-2,996.7 & 2,996.7-3,229.6 & $3,229.6-3,551.6$ & $\geq 3551.6$ \\
\hline Cases/person-years & $735 / 343,836$ & $155 / 68,264$ & $127 / 68,502$ & $149 / 68,646$ & $159 / 69,025$ & $145 / 69,399$ \\
\hline Multivariable model $\mathrm{HR}^{\mathrm{b}}$ & $1.19(1.05,1.35)$ & 1.00 & $1.00(0.78,1.28)$ & $1.24(0.97,1.57)$ & $1.33(1.05,1.68)$ & $1.19(0.93,1.53)$ \\
\hline$P$ value & 0.008 & \multicolumn{5}{|c|}{$P_{\text {trend }}{ }^{c}=0.044$} \\
\hline
\end{tabular}

\footnotetext{
a , mineral intake was energy-adjusted (mg/day), median intake for continuous and range for quintiles. ${ }^{\mathrm{b}}$, Cox proportional hazard models were used to adjust age, body mass index $\left(\mathrm{kg} / \mathrm{m}^{2}\right)$, energy intake ( $\left.\mathrm{kcal} / \mathrm{day}\right)$, educational level (3 categories), alcohol consumption ( $\mathrm{g} /$ day), smoking status (never smokers, former smokers $<20$ pack-years, former smokers $\geq 20$ pack-years, current smokers $<20$ packyears, current smokers $\geq 20$ pack-years), history of diabetes (yes or no), and family history of lung cancer (yes or no) for the PLCO trial or family history of cancer (yes or no) for the WHI cohort. ${ }^{c}$, test for linear trend was estimated by assigning the median value of sodium or potassium intake in each quintile.
} 
A

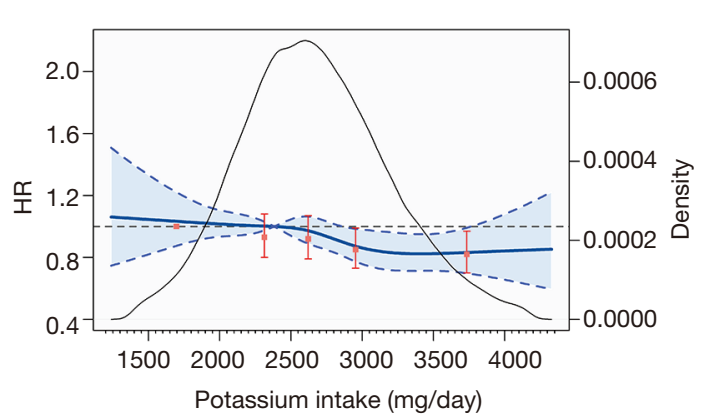

C

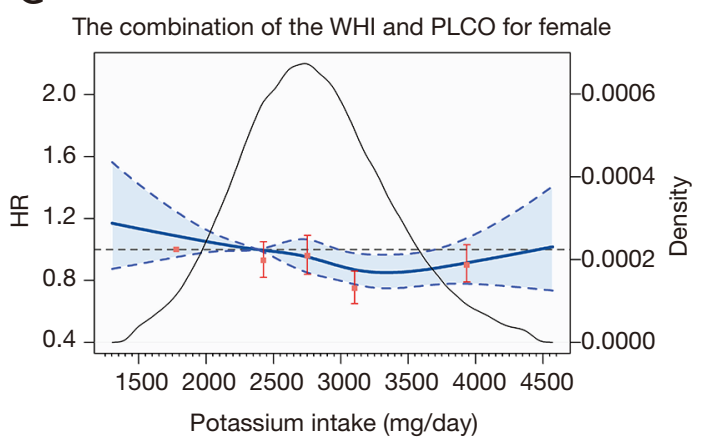

B

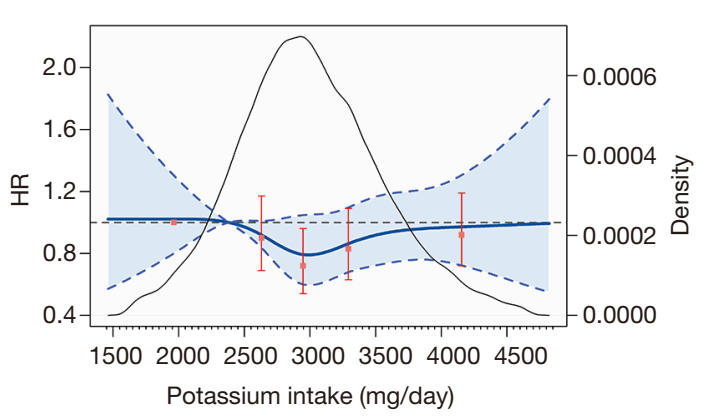

$\mathrm{D}$

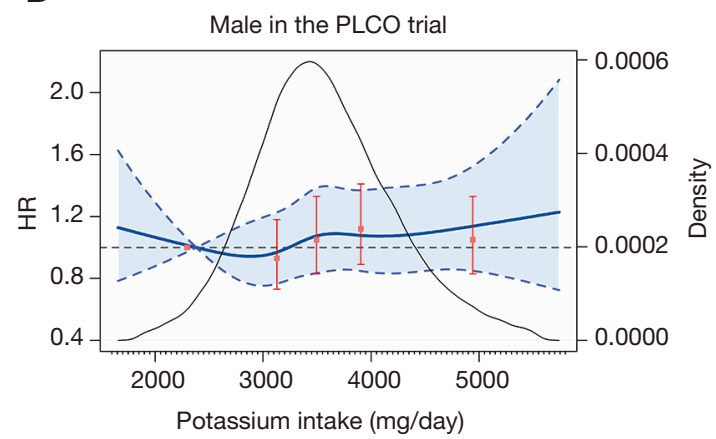

Figure 2 Dose-response association between dietary potassium intake (energy-adjusted) and lung cancer risk for females in the WHI cohort (A), females in the PLCO trial (B), the combination of females (C), and males in the PLCO trial (D) using spline smoothed model. Multivariable risk estimate was calculated to adjust all covariates by spline regression with three knots (20th percentiles as the reference, 2,381 $\mathrm{mg} /$ day). Blue solid line represented point estimates, dashed lines and shadow area represented $95 \%$ confidence intervals. Red solid points and vertical lines represented HRs and 95\% CIs of lung cancer based on categories of dietary potassium intake (compared with the lowest quintile), respectively. Black curve showed the kernel density estimates of participants (right y-axis) consuming of potassium.

in both cohorts. Participants were divided based on the quintiles of mineral intakes in the combined population. The results suggested a quadric relationship between potassium intake and lung cancer risk (Figure $2 C$ ). The HR with the second highest (median intake $3,079 \mathrm{mg} /$ day) versus the lowest quintiles (median intake $1,998 \mathrm{mg} /$ day) of potassium intake was 0.75 (95\% CI: $0.65-0.86$ ), but with no significant difference for the highest quintile (HR: 0.90, 95\% CI: 0.79-1.03) (Table 3). As for sodium intake, although the association was not significant (HR: 1.03, 95\% CI: 0.94-1.13), an upward trend was observed at the end of the spline curve (Figure 3C).

\section{Results from the sensitivity analysis}

After additional adjustment for yogurt intake and race, the results were basically consistent with the above (Tables S4,S5). In the sensitivity analysis using calibrated potassium and sodium intake, consistent dose-response relationship was observed in the WHI cohort (data not shown). Besides, we observed that stratified analyses by smoking status or cancer type showed consistent results with the main analysis, although the association is not significant for SCLC patients due to limited sample size (Tables S6-S9).

\section{Discussion}

To the best of our knowledge, this was the first study to investigate the association between dietary sodium and potassium intake and lung cancer risk. Based on two prospective cohort studies, the association between mineral intake and lung cancer risk was analyzed systematically in our study. The main findings suggested that appropriate intake of potassium was associated with a reduced risk of lung cancer, but once excessive, the protective effect would be weakened. High-level intake of sodium was related to a higher risk of lung cancer for males. However, no significant 

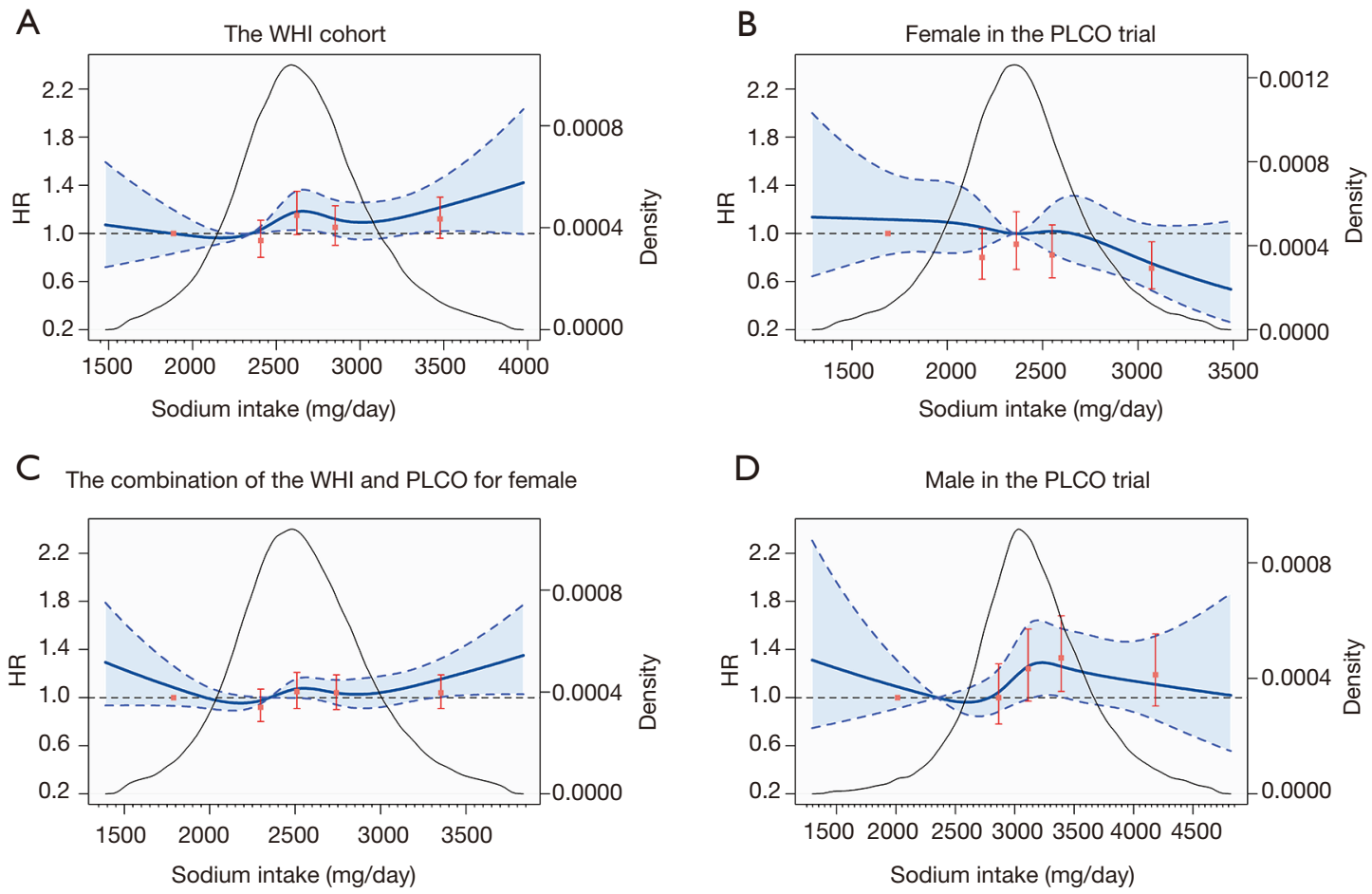

Figure 3 Dose-response association between dietary sodium intake (energy-adjusted) and lung cancer risk for females in the WHI cohort (A), females in the PLCO trial (B), the combination of females (C), and males in the PLCO trial (D) using spline smoothed model. Multivariable risk estimate was calculated to adjust all covariates by spline regression with three knots (20th percentiles as the reference, 2,349 mg/day). Blue solid line represented point estimates, dashed lines and shadow area represented $95 \%$ confidence intervals. Red solid points and vertical lines represented HRs and 95\% CIs of lung cancer based on categories of dietary sodium intake (compared with the lowest quintile), respectively. Black curve showed the kernel density estimates of participants (right y-axis) consuming of sodium.

correlation was observed for females due to the low overall consumption of sodium.

\section{Principal findings and biological rationale}

In the present study, a protective effect against lung cancer risk was observed in females with appropriate high-level intake of potassium in both cohorts. As the spline regression plots shown, the HRs had a quadratic curve correlation with the increase of potassium intake in the PLCO trial, but a linear downward trend in the WHI cohort. A possible explanation for different patterns in the two cohorts maybe related to different levels of potassium intake. Additionally, the median intake for females in the WHI cohort was less than that in the PLCO trial. Thus, the ascending part of the curve could possibly be unobserved due to lack of participants with high-level consumption of potassium.

Emerging evidence suggests that the necrosis of tumor cells can release an intracellular ion and potassium into extracellular fluid. The increased concentration of extracellular potassium leads to increased intracellular potassium within T-cells, which acts to impair T-cells receptor (TCR)-driven Akt-mTOR phosphorylation and effector programs. This can cause a profound suppression of T-cells effector function $(21,22)$. T-cells can recognize the neoantigens, generated by the tumor cells, and then target and kill the cells that may be cancerous. In addition, T-cells also produce chemicals to help regulate the immune response and protect against tumors (23). Lacking of potassium intake is associated with the lower lung function (24). And there are evidences suggesting that potatoes, tomatoes, bananas and yogurt which are all rich in potassium can reduce the incidence of lung cancer effectively $(25,26)$. In combination with the above-mentioned studies, our results indicated that appropriately increasing potassium intake could strengthen the lung function and decrease the incidence of lung cancer. However, once potassium intake exceeded the daily requirement, the concentration 
Table 3 Hazard ratios and 95\% confidence intervals of lung cancer based on categories of dietary potassium intake for female

\begin{tabular}{|c|c|c|c|c|c|c|}
\hline & Quintile 1 & Quintile 2 & Quintile 3 & Quintile 4 & Quintile 5 & $\mathrm{P}_{\text {trend }}{ }^{\mathrm{c}}$ \\
\hline \multicolumn{7}{|l|}{ PLCO $(\mathrm{N}=48,025)$} \\
\hline Cases/person-years & $78 / 44,846$ & $80 / 60,993$ & $108 / 78,777$ & $106 / 93,023$ & $171 / 113,353$ & \\
\hline Multivariable model $\mathrm{HR}^{\mathrm{b}}$ & 1.00 & $0.87(0.63,1.19)$ & $0.87(0.65,1.18)$ & $0.71(0.53,0.97)$ & $0.87(0.66,1.15)$ & 0.359 \\
\hline Cases/person-years & $461 / 269,115$ & $379 / 256,249$ & $342 / 228,387$ & $230 / 204,040$ & $219 / 165,679$ & \\
\hline Multivariable model $\mathrm{HR}^{\mathrm{b}}$ & 1.00 & $0.94(0.82,1.08)$ & $0.98(0.85,1.13)$ & $0.75(0.64,0.89)$ & $0.90(0.76,1.06)$ & 0.023 \\
\hline \multicolumn{7}{|l|}{$\operatorname{ALL}(\mathrm{N}=120,450)$} \\
\hline Cases/person-years & $539 / 313,961$ & $459 / 317,242$ & $450 / 307,165$ & $336 / 297,063$ & $390 / 279,032$ & \\
\hline \multicolumn{7}{|l|}{ PLCO (N=48,025) } \\
\hline Cases/person-years & $184 / 114,533$ & $141 / 103,569$ & $101 / 80,981$ & $75 / 55,696$ & $42 / 36,213$ & \\
\hline Multivariable model $\mathrm{HR}^{\mathrm{b}}$ & 1.00 & $1.01(0.81,1.27)$ & $0.93(0.72,1.19)$ & $0.95(0.72,1.25)$ & $0.76(0.54,1.07)$ & 0.150 \\
\hline \multicolumn{7}{|l|}{ WHI $(\mathrm{N}=72,425)$} \\
\hline Cases/person-years & $234 / 151,282$ & $222 / 175,731$ & $333 / 220,300$ & $387 / 269,553$ & $455 / 306,604$ & \\
\hline Multivariable model $\mathrm{HR}^{\mathrm{b}}$ & 1.00 & $0.91(0.75,1.09)$ & $1.14(0.96,1.36)$ & $1.10(0.93,1.30)$ & $1.12(0.95,1.32)$ & 0.05 \\
\hline \multicolumn{7}{|l|}{$\operatorname{ALL}(\mathrm{N}=120,450)$} \\
\hline Cases/person-years & $418 / 265,815$ & $363 / 279,300$ & $434 / 301,281$ & $462 / 325,249$ & $497 / 342,817$ & \\
\hline
\end{tabular}

of potassium in microenvironment would increase, which could suppress the activity of T-cells and eventually reduce the protective effect on the occurrence of lung cancer.

The biological mechanisms underlying the association between lung cancer risk and intake of sodium remain unclear. Zhang et al. found that high salt intake, a major source of dietary sodium, increased the proinflammatory gene expression of mouse alveolar macrophages and aggravated inflammation in lungs, which was associated with the risk of lung cancer (27). Several cohort studies exhibited that high salt dietary was associated with an increased risk and mortality of lung cancer (28-30). In the present study, an association was found between an increased risk of lung cancer and higher sodium consumption for males in the
PLCO trial and a borderline effect in the WHI cohort. An inconsistent borderline effect was also shown for females in the PLCO trial. It was worth noting that the overall energy-adjusted sodium intake of females in the PLCO trial was less than that of females in the WHI cohort and males in the PLCO trial. And females in the PLCO trial, especially those with higher quintiles, had a high proportion of ibuprofen use, which may contribute to lung cancer prevention (31). In addition, it was plausible that some potential lung cancer patients may not be diagnosed due to the shorter follow-up time for the PLCO trial than WHI cohort, with the median follow-up of 8.55 and 18.56 years respectively.

To date, a growing number of studies show the role of 
dietary mineral intake in the development of cancer. For instance, copper and magnesium can maintain the integrity of DNA by preventing oxidative DNA damage $(32,33)$. Calcium plays an important role in the processes of cell proliferation and carcinogenesis by affecting the cell cycle regulation (34). Minerals participate in various processes of DNA repair, RNA expression, protein synthesis, immune function and so on (21,35-37). In the present study, sodium and potassium, two of the most important minerals in diet, was shown to involve in the cancer genesis.

Lacking of potassium intake and excessive intake of sodium can elevate the blood pressure and the risk of cardiovascular disease, stroke and coronary heart disease (38). A recent study has shown that replacement of regular salt with potassium-enriched substitutes is conductive to reducing the blood pressure (39). The World Health Organization suggests a potassium intake of at least 3,510 mg per day and a reduction of sodium to less than 2,000 $\mathrm{mg}$ per day for adults (40). These all recommend a healthy dietary pattern of high potassium and low sodium, further verifying the reliability of our conclusion.

\section{Strengths and limitations of this study}

There were several strengths in our study. First, this study was made based on the PLCO trial and the WHI which were large-scale, prospective, cohort studies with a relative complete follow-up information (41). Secondly, the combination of the two large-scale cohorts provided sufficient power to detect the association. Nevertheless, several limitations needed to be noted, including only description of the dietary baseline information, possible residual confounding or confounding by unmeasured factors, and the accuracy of dietary intake measurement.

\section{Conclusions}

Our results suggest that appropriate consumption of potassium has a protective effect against lung cancer; high consumption of sodium is related to an increased risk of lung cancer, along with the presence of a dose-response relationship despite the modest magnitude of estimate.

\section{Acknowledgments}

We gratefully thank all PLCO and WHI participants and staff for their time and commitment to these studies. The funders had no role in study design, collection, analysis, interpretation of data, writing of the report or decision to publish or preparation of the manuscript.

Funding: This work is supported by the National Natural Science Foundation of China (Project No. 81872709 to YZ, 81530088 to FC, 81830100 to ZBH, 81820108028 to H.B. S., 81922061 to HXM); Key Project of the Natural Science Foundation of the Jiangsu Higher Education Institutions of China (18KJA110004 to YZ); and the Qing-lan Project of Jiangsu Province and Excellent Young Faculty Program of NMU.

\section{Footnote}

Reporting Checklist: The authors have completed the STROBE reporting checklist. Available at http://dx.doi. org/10.21037/tlcr-20-870

Peer Review File: Available at http://dx.doi.org/10.21037/ tlcr-20-870

Conflicts of Interest: All authors have completed the ICMJE uniform disclosure form (available at http://dx.doi. org/10.21037/tlcr-20-870). The authors have no conflicts of interest to declare.

Ethical Statement: The authors are accountable for all aspects of the work in ensuring that questions related to the accuracy or integrity of any part of the work are appropriately investigated and resolved. The study was conducted in accordance with the Declaration of Helsinki (as revised in 2013). The usage of the lung cancer database in the PLCO and WHI studies was authorized by the ethics committees of the data providers and Nanjing Medical University.

Open Access Statement: This is an Open Access article distributed in accordance with the Creative Commons Attribution-NonCommercial-NoDerivs 4.0 International License (CC BY-NC-ND 4.0), which permits the noncommercial replication and distribution of the article with the strict proviso that no changes or edits are made and the original work is properly cited (including links to both the formal publication through the relevant DOI and the license). See: https://creativecommons.org/licenses/by-nc-nd/4.0/.

\section{References}

1. Ferlay J, Soerjomataram I, Dikshit R, et al. Cancer 
incidence and mortality worldwide: sources, methods and major patterns in GLOBOCAN 2012. Int J Cancer 2015;136:E359-86.

2. Bray F, Ferlay J, Soerjomataram I, et al. Global cancer statistics 2018: GLOBOCAN estimates of incidence and mortality worldwide for 36 cancers in 185 countries. CA Cancer J Clin 2018;68:394-424.

3. Mao Y, Yang D, He J, et al. Epidemiology of Lung Cancer. Surg Oncol Clin N Am 2016;25:439-45.

4. Muka T, Kraja B, Ruiter R, et al. Dietary mineral intake and lung cancer risk: the Rotterdam Study. Eur J Nutr 2017;56:1637-46.

5. Mahabir S, Forman MR, Dong YQ, et al. Mineral intake and lung cancer risk in the NIH-American Association of Retired Persons Diet and Health study. Cancer Epidemiol Biomarkers Prev 2010;19:1976-83.

6. Zhou W, Park S, Liu G, et al. Dietary iron, zinc, and calcium and the risk of lung cancer. Epidemiology 2005;16:772-9.

7. Zhuo H, Smith AH, Steinmaus C. Selenium and lung cancer: a quantitative analysis of heterogeneity in the current epidemiological literature. Cancer Epidemiol Biomarkers Prev 2004;13:771-8.

8. Meng Y, Sun J, Yu J, et al. Dietary Intakes of Calcium, Iron, Magnesium, and Potassium Elements and the Risk of Colorectal Cancer: a Meta-Analysis. Biol Trace Elem Res 2019;189:325-35.

9. Kune GA, Kune S, Watson LF. Dietary sodium and potassium intake and colorectal cancer risk. Nutr Cancer 1989;12:351-9.

10. Deckers IA, van den Brandt PA, van Engeland M, et al. Long-term dietary sodium, potassium and fluid intake; exploring potential novel risk factors for renal cell cancer in the Netherlands Cohort Study on diet and cancer. Br J Cancer 2014;110:797-801.

11. Peleteiro B, Barros S, Castro C, et al. Worldwide burden of gastric cancer in 2010 attributable to high sodium intake in 1990 and predicted attributable burden for 2030 based on exposures in 2010. Br J Nutr 2016;116:728-33.

12. Prorok PC, Andriole GL, Bresalier RS, et al. Design of the Prostate, Lung, Colorectal and Ovarian (PLCO) Cancer Screening Trial. Control Clin Trials 2000;21:273S-309S.

13. Xu X. Processed Meat Intake and Bladder Cancer Risk in the Prostate, Lung, Colorectal, and Ovarian (PLCO) Cohort. Cancer Epidemiol Biomarkers Prev 2019;28:1993-7.

14. Langer RD, White E, Lewis CE, et al. The Women's Health Initiative Observational Study: baseline characteristics of participants and reliability of baseline measures. Ann Epidemiol 2003;13:S107-21.

15. Design of the Women's Health Initiative clinical trial and observational study. The Women's Health Initiative Study Group. Control Clin Trials 1998;19:61-109.

16. Subar AF, Midthune D, Kulldorff M, et al. Evaluation of alternative approaches to assign nutrient values to food groups in food frequency questionnaires. Am J Epidemiol 2000;152:279-86.

17. Willett WC, Howe GR, Kushi LH. Adjustment for total energy intake in epidemiologic studies. Am J Clin Nutr 1997;65:1220S-1228S; discussion 1229S-1231S.

18. Marrie RA, Dawson NV, Garland A. Quantile regression and restricted cubic splines are useful for exploring relationships between continuous variables. J Clin Epidemiol 2009;62:511-7.

19. Yang JJ, Yu D, Xiang YB, et al. Association of Dietary Fiber and Yogurt Consumption with Lung Cancer Risk: A Pooled Analysis. JAMA Oncol 2020;6:e194107.

20. Huang Y, Van Horn L, Tinker LF, et al. Measurement error corrected sodium and potassium intake estimation using 24-hour urinary excretion. Hypertension 2014;63:238-44.

21. Eil R, Vodnala SK, Clever D, et al. Ionic immune suppression within the tumour microenvironment limits $\mathrm{T}$ cell effector function. Nature 2016;537:539-43.

22. Vodnala SK, Eil R, Kishton RJ, et al. T cell stemness and dysfunction in tumors are triggered by a common mechanism. Science 2019;363:eaau0135.

23. Dunn GP, Bruce AT, Ikeda H, et al. Cancer immunoediting: from immunosurveillance to tumor escape. Nat Immunol 2002;3:991-8.

24. Gilliland FD, Berhane KT, Li YF, et al. Dietary magnesium, potassium, sodium, and children's lung function. Am J Epidemiol 2002;155:125-31.

25. Ruano-Ravina A, Figueiras A, Dosil-Diaz O, et al. A population-based case-control study on fruit and vegetable intake and lung cancer: a paradox effect? Nutr Cancer 2002;43:47-51.

26. Agudo A, Esteve MG, Pallares C, et al. Vegetable and fruit intake and the risk of lung cancer in women in Barcelona, Spain. Eur J Cancer 1997;33:1256-61.

27. Zhang WC, Zheng XJ, Du LJ, et al. High salt primes a specific activation state of macrophages, $\mathrm{M}(\mathrm{Na})$. Cell Res 2015;25:893-910.

28. Suadicani P, Hein HO, Gyntelberg F. ABO phenotypes and inflammation-related predictors of lung cancer mortality: the Copenhagen Male Study - a 16-year follow- 
up. Eur Respir J 2007;30:13-20.

29. Hu J, La Vecchia C, Morrison H, et al. Salt, processed meat and the risk of cancer. Eur J Cancer Prev 2011;20:132-9.

30. Wakai K, Ohno Y, Genka K, et al. Risk modification in lung cancer by a dietary intake of preserved foods and soyfoods: findings from a case-control study in Okinawa, Japan. Lung Cancer 1999;25:147-59.

31. Bittoni MA, Carbone DP, Harris RE. Ibuprofen and fatal lung cancer: A brief report of the prospective results from the Third National Health and Nutrition Examination Survey (NHANES III). Mol Clin Oncol 2017;6:917-20.

32. Uriu-Adams JY, Keen CL. Copper, oxidative stress, and human health. Mol Aspects Med 2005;26:268-98.

33. Mahabir S, Wei Q, Barrera SL, et al. Dietary magnesium and DNA repair capacity as risk factors for lung cancer. Carcinogenesis 2008;29:949-56.

34. Peterlik M, Grant WB, Cross HS. Calcium, vitamin D and cancer. Anticancer Res 2009;29:3687-98.

35. Ho E. Zinc deficiency, DNA damage and cancer risk. J

Cite this article as: You D, Zhang M, He W, Wang D, Yu Y, Yu Z, Lange T, Yang S, Wei Y, Ma H, Hu Z, Shen H, Chen F, Zhao Y. Association between dietary sodium, potassium intake and lung cancer risk: evidence from the prostate, lung, colorectal and ovarian cancer screening trial and the Women's Health Initiative. Transl Lung Cancer Res 2021;10(1):45-56. doi: $10.21037 /$ tlcr-20-870
Nutr Biochem 2004;15:572-8.

36. Beckett EL, Yates Z, Veysey M, et al. The role of vitamins and minerals in modulating the expression of microRNA. Nutr Res Rev 2014;27:94-106.

33. Prasad AS. Zinc: role in immunity, oxidative stress and chronic inflammation. Curr Opin Clin Nutr Metab Care 2009;12:646-52.

33. Chmielewski J, Carmody JB. Dietary sodium, dietary potassium, and systolic blood pressure in US adolescents. J Clin Hypertens (Greenwich) 2017;19:904-9.

33. Bernabe-Ortiz A, Sal YRV, Ponce-Lucero V, et al. Effect of salt substitution on community-wide blood pressure and hypertension incidence. Nat Med 2020;26:374-8.

40. Guideline: Potassium Intake for Adults and Children. Geneva: World Health Organization, 2012.

41. Andriole GL, Levin DL, Crawford ED, et al. Prostate Cancer Screening in the Prostate, Lung, Colorectal and Ovarian (PLCO) Cancer Screening Trial: findings from the initial screening round of a randomized trial. J Natl Cancer Inst 2005;97:433-8. 


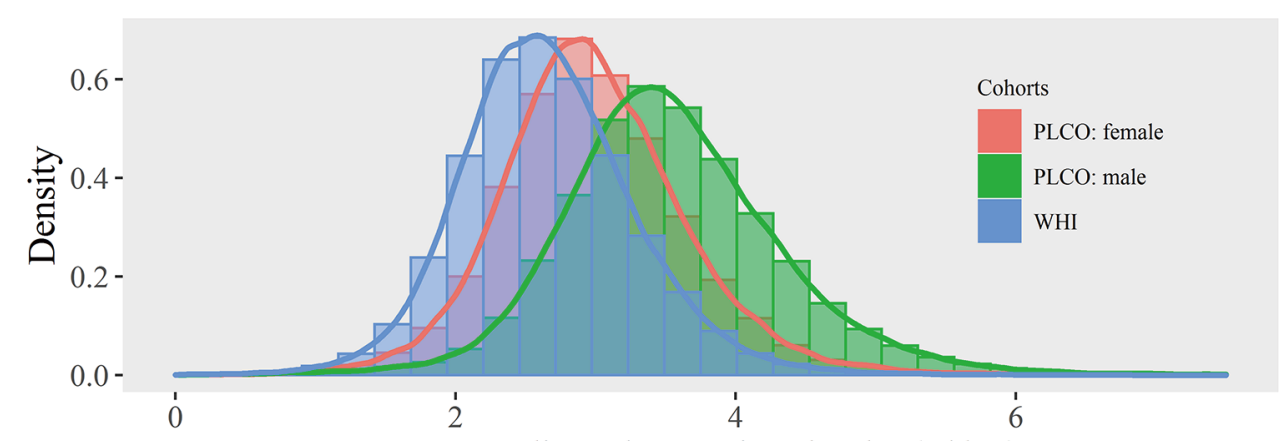

Energy-adjusted potassium intake (g/day)

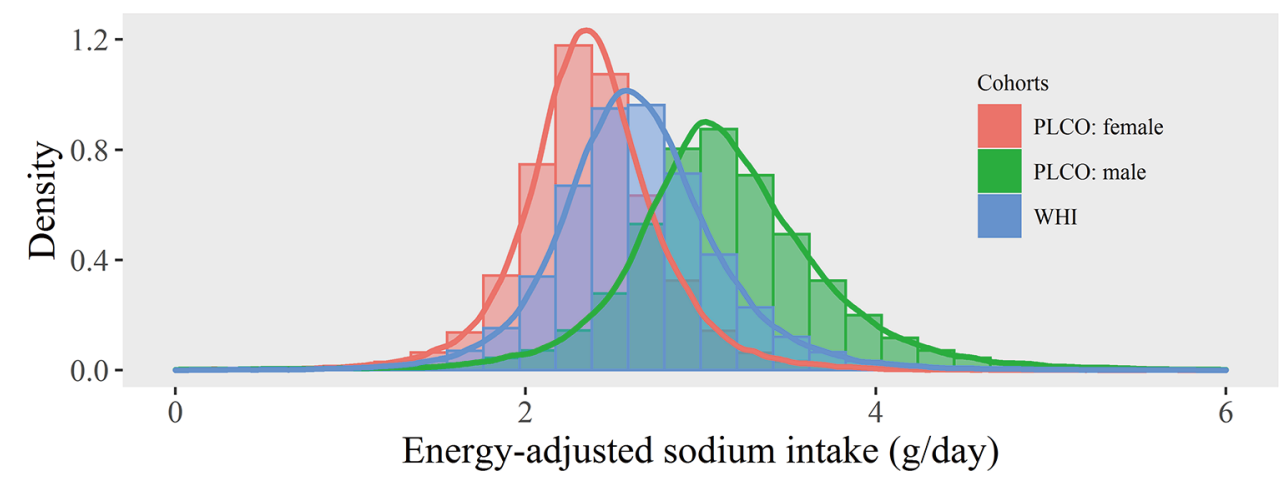

Figure S1 The distributions of potassium and sodium intake in the PLCO and WHI cohorts. Solid lines represented kernel density estimates. 
Table S1 Baseline characteristics of the study population in the PLCO trial based on quintiles of sodium and potassium intake

\begin{tabular}{|c|c|c|c|c|c|c|c|c|c|c|c|c|}
\hline \multirow{2}{*}{$\begin{array}{l}\text { Baseline characteristics } \\
\text { Quintiles }^{a}\end{array}$} & \multicolumn{6}{|c|}{ Sodium } & \multicolumn{6}{|c|}{ Potassium } \\
\hline & 1 (low) & 2 & 3 & 4 & 5 (high) & $P$ value $^{d}$ & 1 (low) & 2 & 3 & 4 & 5 (high) & $P$ value ${ }^{d}$ \\
\hline Total (N) & 18597 & 18597 & 18597 & 18597 & 18596 & & 18597 & 18597 & 18597 & 18597 & 18596 & \\
\hline No. of lung cancer (n) & 299 & 229 & 238 & 265 & 247 & & 273 & 243 & 243 & 247 & 272 & \\
\hline $\begin{array}{l}\text { Median mineral intake } \\
(\mathrm{mg} / \mathrm{day})^{\mathrm{b}}\end{array}$ & 2201.5 & 2526.2 & 2719.2 & 2932.2 & 3329.6 & $<0.001$ & 2410.4 & 2878.9 & 3203.5 & 3567.7 & 4177.1 & $<0.001$ \\
\hline Age $\left(\right.$ year) ${ }^{c}$ & $62.5 \pm 5.4$ & $62.6 \pm 5.3$ & $62.4 \pm 5.3$ & $62.2 \pm 5.2$ & $61.9 \pm 5.1$ & $<0.001$ & $61.8 \pm 5.2$ & $62.3 \pm 5.2$ & $62.5 \pm 5.3$ & $62.6 \pm 5.3$ & $62.5 \pm 5.3$ & $<0.001$ \\
\hline \multicolumn{13}{|l|}{ Gender (\%) } \\
\hline Female & 45.8 & 58.6 & 58.5 & 54.6 & 40.7 & $<0.001$ & 41.1 & 52.6 & 55.3 & 56.1 & 53.1 & $<0.001$ \\
\hline Male & 54.2 & 41.4 & 41.5 & 45.4 & 59.3 & & 58.9 & 47.4 & 44.7 & 43.9 & 46.9 & \\
\hline Body mass index $\left(\mathrm{kg} / \mathrm{m}^{2}\right)^{\mathrm{c}}$ & $26.6 \pm 4.5$ & $26.7 \pm 4.6$ & $27.1 \pm 4.7$ & $27.6 \pm 4.9$ & $28.3 \pm 5.1$ & $<0.001$ & $27.7 \pm 4.9$ & $27.4 \pm 4.8$ & $27.2 \pm 4.8$ & $27.0 \pm 4.7$ & $27.0 \pm 4.7$ & $<0.001$ \\
\hline \multicolumn{13}{|l|}{ Education (\%) } \\
\hline Low & 28.9 & 29.3 & 28.6 & 28.2 & 28.3 & 0.100 & 32.6 & 29.5 & 28.2 & 27.0 & 26.0 & $<0.001$ \\
\hline Middle & 34.8 & 34.5 & 34.4 & 34.7 & 34.0 & & 34.5 & 34.9 & 34.7 & 34.3 & 34.0 & \\
\hline High & 36.3 & 36.2 & 37.0 & 37.1 & 37.7 & & 32.9 & 35.6 & 37.1 & 38.7 & 40.0 & \\
\hline \multicolumn{13}{|l|}{ Cigarette smoking (\%) } \\
\hline Never & 44.9 & 51.2 & 51.1 & 48.5 & 43.6 & $<0.001$ & 47.2 & 49.8 & 49.2 & 48.0 & 45.2 & $<0.001$ \\
\hline Former $<20$ pack-years & 18.6 & 18.6 & 18.9 & 18.4 & 18.5 & & 16.7 & 18.2 & 19.0 & 19.4 & 19.7 & \\
\hline Former $\geq 20$ pack-years & 24.4 & 21.7 & 22.1 & 24.7 & 28.5 & & 25.1 & 23.3 & 23.6 & 24.0 & 25.5 & \\
\hline Current $<20$ pack-years & 0.9 & 0.8 & 0.7 & 0.8 & 0.8 & & 0.9 & 0.8 & 0.7 & 0.8 & 0.8 & \\
\hline Current $\geq 20$ pack-years & 11.2 & 7.7 & 7.2 & 7.4 & 8.6 & & 10.2 & 7.9 & 7.5 & 7.8 & 8.8 & \\
\hline Alcohol intake $(\mathrm{g} / \text { day })^{\mathrm{c}}$ & $23.5 \pm 50.4$ & $7.6 \pm 12.9$ & $6.1 \pm 11.1$ & $5.7 \pm 10.1$ & $5.9 \pm 10.6$ & $<0.001$ & $18.9 \pm 48.6$ & $8.5 \pm 17.1$ & $7.6 \pm 13.9$ & $7.2 \pm 13.1$ & $6.7 \pm 12.3$ & $<0.001$ \\
\hline Energy intake $(\mathrm{kcal} / \mathrm{day})^{\mathrm{c}}$ & $1951 \pm 831$ & $1506 \pm 620$ & $1507 \pm 607$ & $1652 \pm 618$ & $2088 \pm 766$ & $<0.001$ & $1928 \pm 899$ & $1585 \pm 678$ & $1587 \pm 634$ & $1664 \pm 629$ & $1940 \pm 708$ & $<0.001$ \\
\hline Diabetes (\%) & 3.3 & 4.3 & 5.8 & 7.7 & 11.5 & $<0.001$ & 5.7 & 6.6 & 6.5 & 6.7 & 7.1 & $<0.001$ \\
\hline $\begin{array}{l}\text { Family history of lung } \\
\text { cancer (\%) }\end{array}$ & 11.0 & 10.6 & 10.3 & 10.6 & 11.1 & 0.090 & 10.4 & 10.5 & 11.0 & 11.0 & 10.6 & 0.153 \\
\hline
\end{tabular}

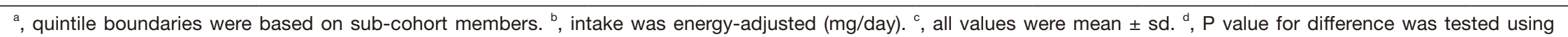
Kruskal-Wallis test (continuous) or Chi-square test (categorical). 
Table S2 Baseline characteristics of the study population in the WHI cohort based on quintiles of sodium and potassium intake

\begin{tabular}{|c|c|c|c|c|c|c|c|c|c|c|c|c|}
\hline \multirow{2}{*}{$\begin{array}{l}\text { Baseline characteristics } \\
\text { Quintiles }^{a}\end{array}$} & \multicolumn{6}{|c|}{ Sodium } & \multicolumn{6}{|c|}{ Potassium } \\
\hline & 1 (low) & 2 & 3 & 4 & 5 (high) & $P$ value ${ }^{d}$ & 1 (low) & 2 & 3 & 4 & 5 (high) & $P$ value $^{d}$ \\
\hline Total (N) & 14485 & 14485 & 14485 & 14485 & 14485 & & 14485 & 14485 & 14485 & 14485 & 14485 & \\
\hline No. of lung cancer (n) & 337 & 293 & 343 & 313 & 345 & & 368 & 336 & 332 & 304 & 291 & \\
\hline Median mineral intake $(\mathrm{mg} / \text { day })^{\mathrm{b}}$ & 2100.8 & 2416.7 & 2620.2 & 2835.3 & 3212.1 & $<0.001$ & 1914.1 & 2324.2 & 2619.5 & 2934.5 & 3450.3 & $<0.001$ \\
\hline Age $(\text { year })^{c}$ & $63.1 \pm 7.4$ & $63.5 \pm 7.3$ & $63.5 \pm 7.3$ & $63.4 \pm 7.3$ & $63.3 \pm 7.2$ & $<0.001$ & $62.2 \pm 7.3$ & $63.2 \pm 7.4$ & $63.5 \pm 7.2$ & $63.8 \pm 7.3$ & $64.2 \pm 7.2$ & $<0.001$ \\
\hline Body mass index $\left(\mathrm{kg} / \mathrm{m}^{2}\right)^{c}$ & $27.1 \pm 5.9$ & $26.8 \pm 5.6$ & $27.0 \pm 5.6$ & $27.3 \pm 5.8$ & $27.8 \pm 6.1$ & $<0.001$ & $28.9 \pm 6.7$ & $27.3 \pm 5.8$ & $26.8 \pm 5.5$ & $26.6 \pm 5.4$ & $26.3 \pm 5.2$ & $<0.001$ \\
\hline \multicolumn{13}{|l|}{ Education (\%) } \\
\hline Low & 22.7 & 21.8 & 21.0 & 19.9 & 19.0 & $<0.001$ & 32.1 & 23.3 & 19.1 & 16.4 & 13.5 & $<0.001$ \\
\hline Middle & 36.8 & 36.6 & 36.6 & 35.6 & 35.5 & & 38.2 & 38.0 & 36.5 & 35.4 & 33.2 & \\
\hline High & 40.5 & 41.6 & 42.4 & 44.5 & 45.5 & & 29.7 & 38.7 & 44.4 & 48.2 & 53.3 & \\
\hline \multicolumn{13}{|l|}{ Cigarette smoking (\%) } \\
\hline Never & 50.6 & 53.5 & 54.0 & 53.2 & 50.2 & $<0.001$ & 51.2 & 52.3 & 52.3 & 52.2 & 53.5 & $<0.001$ \\
\hline Former $<20$ pack-years & 25.8 & 26.6 & 26.7 & 26.8 & 28.2 & & 23.5 & 25.8 & 27.4 & 28.9 & 28.5 & \\
\hline Former $\geq 20$ pack-years & 14.8 & 13.3 & 13.7 & 15.0 & 16.6 & & 14.4 & 14.9 & 15.0 & 14.5 & 14.6 & \\
\hline Current $<20$ pack-years & 3.0 & 2.7 & 2.3 & 2.0 & 2.1 & & 3.9 & 2.9 & 2.2 & 1.7 & 1.4 & \\
\hline Current $\geq 20$ pack-years & 5.8 & 3.9 & 3.3 & 3.0 & 2.9 & & 7.0 & 4.1 & 3.1 & 2.7 & 2.0 & \\
\hline Alcohol intake $(\mathrm{g} / \text { day })^{\mathrm{C}}$ & $9.50 \pm 17.9$ & $5.72 \pm 10.0$ & $4.68 \pm 8.3$ & $4.14 \pm 7.6$ & $3.82 \pm 7.3$ & $<0.001$ & $5.24 \pm 12.7$ & $5.75 \pm 11.2$ & $5.91 \pm 11.0$ & $5.80 \pm 10.5$ & $5.17 \pm 10.2$ & $<0.001$ \\
\hline Energy intake (kcal/day) ${ }^{c}$ & $1762 \pm 651$ & $1449 \pm 524$ & $1420 \pm 525$ & $1478 \pm 539$ & $1742 \pm 631$ & $<0.001$ & $1722 \pm 751$ & $1437 \pm 563$ & $1452 \pm 526$ & $1520 \pm 503$ & $1718 \pm 534$ & $<0.001$ \\
\hline Diabetes (\%) & 3.3 & 4.0 & 4.8 & 5.8 & 8.2 & $<0.001$ & 6.4 & 5.7 & 4.7 & 4.7 & 4.7 & $<0.001$ \\
\hline Family history of cancer (\%) & 63.4 & 64.0 & 64.7 & 64.0 & 64.4 & 0.171 & 62.3 & 63.6 & 64.5 & 64.4 & 65.6 & $<0.001$ \\
\hline
\end{tabular}

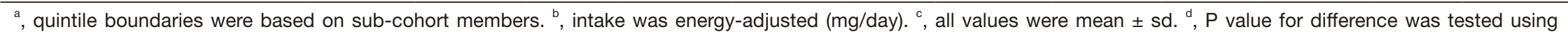
Kruskal-Wallis test (continuous) or Chi-square test (categorical).

Table S3 Correlation coefficients between dietary mineral intake and dietary food sources

\begin{tabular}{|c|c|c|c|c|}
\hline \multirow{2}{*}{ Meals and Nutrients } & \multicolumn{2}{|c|}{ WHI cohort } & \multicolumn{2}{|c|}{ PLCO trial } \\
\hline & Potassium & Sodium & Potassium & Sodium \\
\hline Fruit & 0.574 & 0.162 & 0.511 & 0.178 \\
\hline Vegetable & 0.549 & 0.347 & 0.663 & 0.604 \\
\hline Meat or Protein & 0.799 & 0.888 & 0.515 & 0.731 \\
\hline Fish and seafood & 0.304 & 0.331 & 0.292 & 0.330 \\
\hline Carbohydrate & 0.811 & 0.788 & 0.814 & 0.776 \\
\hline Fiber & 0.782 & 0.663 & 0.791 & 0.701 \\
\hline Milk & 0.605 & 0.303 & 0.412 & 0.207 \\
\hline Yogurt & 0.349 & 0.174 & 0.163 & 0.034 \\
\hline
\end{tabular}

All Pearson's correlation coefficients were significantly different form zero $(P<0.05)$. 
Table S4 Sensitivity analysis of yogurt intake based on categories of dietary potassium intake in the PLCO trial

\begin{tabular}{|c|c|c|c|c|c|c|}
\hline & Continuous & Quintile 1 & Quintile 2 & Quintile 3 & Quintile 4 & Quintile 5 \\
\hline \multicolumn{7}{|l|}{ Male $(\mathrm{N}=44,959)$} \\
\hline Dietary potassium intakea & 3489.9 & $<2935.9$ & 2935.9-3319.7 & $3319.7-3670.0$ & $3670.0-4142.0$ & $\geq 4142.0$ \\
\hline Cases/person-years & $735 / 343836$ & $152 / 68795$ & $127 / 68496$ & $145 / 68642$ & $159 / 68905$ & $152 / 68998$ \\
\hline Multivariable model $\mathrm{HR}^{\mathrm{b}}$ & $1.06(0.97,1.17)$ & 1.00 & $0.93(0.73,1.18)$ & $1.05(0.83,1.33)$ & $1.12(0.89,1.41)$ & $1.05(0.83,1.33)$ \\
\hline$P$ value & 0.191 & & & $P_{\text {trend }}{ }^{c}=0.354$ & & \\
\hline \multicolumn{7}{|l|}{ Female $(\mathrm{N}=48,025)$} \\
\hline Dietary potassium intake & 2943.8 & $<2463.4$ & $2463.4-2797.0$ & $2797.0-3096.8$ & $3096.8-3487.7$ & $\geq 3487.7$ \\
\hline Cases/person-years & $543 / 390992$ & $123 / 77876$ & $106 / 77994$ & $87 / 77975$ & $103 / 78589$ & $124 / 78558$ \\
\hline Multivariable model $\mathrm{HR}^{\mathrm{b}}$ & $0.97(0.86,1.10)$ & 1.00 & $0.90(0.69,1.18)$ & $0.73(0.55,0.96)$ & $0.84(0.64,1.10)$ & $0.94(0.72,1.22)$ \\
\hline$P$ value & 0.629 & & & $\mathrm{P}_{\text {trend }}{ }^{c}=0.633$ & & \\
\hline \multicolumn{7}{|l|}{ ALL $(\mathrm{N}=92,984)$} \\
\hline Dietary potassium intake ${ }^{a}$ & 3203.4 & $<2689.6$ & 2689.6-3044.9 & $3044.9-3371.5$ & $3371.5-3808.0$ & $\geq 3808.0$ \\
\hline Cases/person-years & $1278 / 734829$ & $273 / 145886$ & $243 / 146337$ & $243 / 146963$ & $247 / 147928$ & $272 / 147715$ \\
\hline Multivariable model $\mathrm{HR}^{\mathrm{b}}$ & $1.03(0.96,1.11)$ & 1.00 & $1.01(0.85,1.21)$ & $1.01(0.85,1.21)$ & $1.01(0.84,1.20)$ & $1.05(0.88,1.25)$ \\
\hline$P$ value & 0.437 & & & $P_{\text {trend }}{ }^{c}=0.607$ & & \\
\hline
\end{tabular}

a, potassium intake was energy-adjusted (mg/day), median intake for continuous and range for quintiles. ${ }^{\mathrm{b}}$, Cox proportional hazard models were used to adjust age, gender (only in ALL), body mass index $\left(\mathrm{kg} / \mathrm{m}^{2}\right)$, energy intake ( $\mathrm{kcal} /$ day), educational level (3 categories), alcohol consumption ( $\mathrm{g} /$ day), yogurt consumption ( $\mathrm{g} /$ day), smoking status (never smokers, former smokers $<20$ pack-years, former smokers $\geq 20$ pack-years, current smokers $<20$ pack-years, current smokers $\geq 20$ pack-years), history of diabetes (yes or no), and family history of lung cancer (yes or no). ${ }^{\circ}$, test for linear trend was estimated by assigning the median value of potassium intake in each quintile. 
Table S5 Sensitivity analysis of race based on categories of dietary mineral intake

\begin{tabular}{|c|c|c|c|c|c|c|}
\hline & Continuous & Quintile 1 & Quintile 2 & Quintile 3 & Quintile 4 & Quintile 5 \\
\hline \multicolumn{7}{|l|}{ Potassium } \\
\hline \multicolumn{7}{|l|}{ WHI (female only) } \\
\hline Dietary intake $^{a}$ & 2619.5 & $<2153.6$ & $2153.6-2473.8$ & 2473.8-2768.2 & 2768.2-3139.5 & $\geq 3139.5$ \\
\hline Cases/person-years & $1631 / 1123470$ & $368 / 207916$ & $336 / 220409$ & $332 / 228708$ & $304 / 231972$ & $291 / 234465$ \\
\hline Multivariable model $\mathrm{HR}^{\mathrm{b}}$ & $0.94(0.86,1.02)$ & 1.00 & $0.93(0.80,1.09)$ & $0.92(0.78,1.07)$ & $0.84(0.72,0.99)$ & $0.82(0.69,0.96)$ \\
\hline$P$ value & 0.112 & & & $P_{\text {trend }}{ }^{c}=0.007$ & & \\
\hline \multicolumn{7}{|l|}{ Female in the PLCO } \\
\hline Dietary intake ${ }^{a}$ & 2943.8 & $<2463.4$ & 2463.4-2797.0 & $2797.0-3096.8$ & $3096.8-3487.7$ & $\geq 3487.7$ \\
\hline Cases/person-years & $543 / 390992$ & $123 / 77876$ & $106 / 77994$ & $87 / 77975$ & $103 / 78589$ & $124 / 78558$ \\
\hline Multivariable model $\mathrm{HR}^{\mathrm{b}}$ & $0.98(0.87,1.11)$ & 1.00 & $0.92(0.70,1.20)$ & $0.73(0.55,0.98)$ & $0.85(0.65,1.12)$ & $0.95(0.74,1.23)$ \\
\hline$P$ value & 0.725 & & & $\mathrm{P}_{\text {trend }}{ }^{\mathrm{c}}=0.715$ & & \\
\hline \multicolumn{7}{|l|}{ Male in the PLCO } \\
\hline Dietary intake ${ }^{a}$ & 3489.9 & $<2935.9$ & 2935.9-3319.7 & $3319.7-3670.0$ & $3670.0-4142.0$ & $\geq 4142.0$ \\
\hline Cases/person-years & $735 / 343836$ & $152 / 68795$ & $127 / 68496$ & $145 / 68642$ & $159 / 68905$ & $152 / 68998$ \\
\hline Multivariable model $\mathrm{HR}^{\mathrm{b}}$ & $1.05(0.95,1.15)$ & 1.00 & $0.90(0.71,1.15)$ & $1.01(0.80,1.29)$ & $1.07(0.85,1.35)$ & $1.01(0.80,1.28)$ \\
\hline$P$ value & 0.346 & & & $P_{\text {trend }}{ }^{c}=0.569$ & & \\
\hline \multicolumn{7}{|l|}{ Sodium } \\
\hline \multicolumn{7}{|l|}{ WHI (female only) } \\
\hline Dietary intake $^{a}$ & 2620.2 & $<2291.5$ & $2291.5-2522.5$ & $2522.5-2722.4$ & $2722.4-2980.3$ & $\geq 2980.3$ \\
\hline Cases/person-years & $1631 / 1123470$ & $337 / 221914$ & $293 / 224463$ & $343 / 224825$ & $313 / 226959$ & $345 / 225309$ \\
\hline Multivariable model $\mathrm{HR}^{\mathrm{b}}$ & $1.09(0.99,1.21)$ & 1.00 & $0.94(0.80,1.11)$ & $1.14(0.98,1.34)$ & $1.04(0.89,1.22)$ & $1.11(0.95,1.30)$ \\
\hline$P$ value & 0.084 & & & $P_{\text {trend }}{ }^{c}=0.093$ & & \\
\hline \multicolumn{7}{|l|}{ Female in the PLCO } \\
\hline Dietary intake ${ }^{a}$ & 2361.2 & $<2083.6$ & 2083.6-2280.3 & $2280.3-2442.9$ & 2442.9-2656.4 & $\geq 2656.4$ \\
\hline Cases/person-years & $543 / 390992$ & $143 / 77508$ & $101 / 78109$ & $106 / 78154$ & $100 / 78802$ & $93 / 78418$ \\
\hline Multivariable model $\mathrm{HR}^{\mathrm{b}}$ & $0.86(0.71,1.04)$ & 1.00 & $0.82(0.63,1.07)$ & $0.93(0.72,1.21)$ & $0.84(0.65,1.10)$ & $0.74(0.56,0.97)$ \\
\hline$P$ value & 0.114 & & & $P_{\text {trend }}{ }^{c}=0.043$ & & \\
\hline \multicolumn{7}{|l|}{ Male in the PLCO } \\
\hline Dietary intake ${ }^{a}$ & 3108.9 & $<2732.1$ & 2732.1-2996.7 & 2996.7-3229.6 & $3229.6-3551.6$ & $\geq 3551.6$ \\
\hline Cases/person-years & $735 / 343836$ & $155 / 68264$ & $127 / 68502$ & $149 / 68646$ & $159 / 69025$ & $145 / 69399$ \\
\hline Multivariable model $\mathrm{HR}^{\mathrm{b}}$ & $1.18(1.04,1.34)$ & 1.00 & $1.00(0.78,1.28)$ & $1.23(0.97,1.56)$ & $1.31(1.04,1.66)$ & $1.18(0.92,1.51)$ \\
\hline$P$ value & 0.011 & & & $P_{\text {trend }}{ }^{c}=0.055$ & & \\
\hline
\end{tabular}

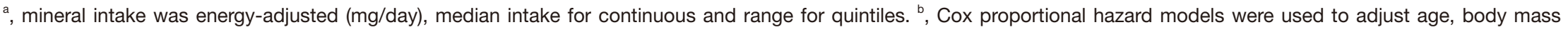

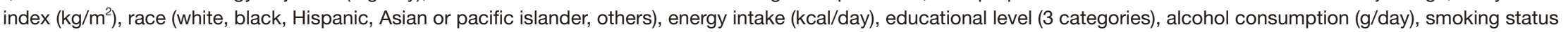

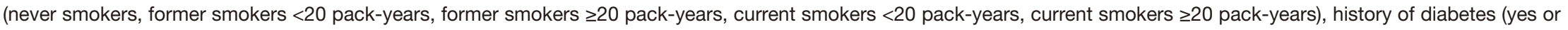

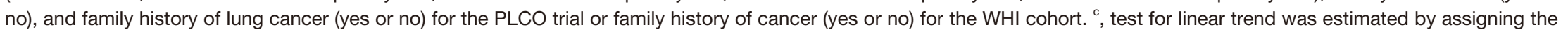
median value of sodium or potassium intake in each quintile. 
Table S6 Smoking-status-specific hazard ratios and 95\% confidence intervals of lung cancer based on categories of dietary sodium intake

\begin{tabular}{|c|c|c|c|c|c|c|}
\hline & Continuous & Quintile 1 & Quintile 2 & Quintile 3 & Quintile 4 & Quintile 5 \\
\hline \multicolumn{7}{|l|}{ PLCO (male, N=44,959) } \\
\hline \multicolumn{7}{|l|}{ Non-smoker } \\
\hline Dietary sodium intake ${ }^{a}$ & 3083.1 & $<2728.9$ & 2728.9-2982.2 & 2982.2-3193.7 & $3193.7-3486.5$ & $\geq 3486.5$ \\
\hline Cases/person-years & $38 / 132602$ & $7 / 26494$ & $8 / 26247$ & $10 / 26296$ & $10 / 26764$ & $3 / 26801$ \\
\hline Multivariable model $\mathrm{HR}^{\mathrm{b}}$ & $1.00(0.52,1.94)$ & 1.00 & $1.05(0.37,2.99)$ & $1.35(0.49,3.69)$ & $1.36(0.50,3.70)$ & $0.45(0.11,1.81)$ \\
\hline \multicolumn{7}{|l|}{ Smoker } \\
\hline Dietary sodium intake ${ }^{a}$ & 3124.7 & $<2733.5$ & $2733.5-3006.1$ & $3006.1-3251.2$ & $3251.2-3588.8$ & $\geq 3588.8$ \\
\hline Cases/person-years & $697 / 211235$ & $144 / 41856$ & $125 / 42163$ & $135 / 42288$ & $153 / 42286$ & $140 / 42642$ \\
\hline Multivariable model $\mathrm{HR}^{\mathrm{b}}$ & $1.15(1.01,1.31)$ & 1.00 & $0.95(0.74,1.22)$ & $1.06(0.83,1.36)$ & $1.23(0.97,1.57)$ & $1.13(0.88,1.46)$ \\
\hline \multicolumn{7}{|l|}{ PLCO (female, N=48,025) } \\
\hline \multicolumn{7}{|l|}{ Non-smoker } \\
\hline Dietary sodium intake ${ }^{a}$ & 2346.0 & $<2075.4$ & 2075.4-2267.9 & $2267.9-2423.1$ & 2423.1-2627.2 & $\geq 2627.2$ \\
\hline Cases/person-years & $67 / 226058$ & $16 / 45162$ & $12 / 45091$ & $11 / 45054$ & $14 / 45381$ & $14 / 45370$ \\
\hline Multivariable model $\mathrm{HR}^{\mathrm{b}}$ & $1.34(0.77,2.35)$ & 1.00 & $0.77(0.36,1.65)$ & $0.74(0.34,1.62)$ & $0.98(0.47,2.05)$ & $1.04(0.50,2.16)$ \\
\hline \multicolumn{7}{|l|}{ Smoker } \\
\hline Dietary sodium intake ${ }^{a}$ & 2381.4 & $<2093.0$ & 2093.0-2297.8 & $2297.8-2469.7$ & 2469.7-2698.1 & $\geq 2698.1$ \\
\hline Cases/person-years & $476 / 164935$ & $128 / 32360$ & $88 / 33054$ & $97 / 33042$ & $90 / 33430$ & $73 / 33049$ \\
\hline Multivariable model $\mathrm{HR}^{\mathrm{b}}$ & $0.75(0.61,0.93)$ & 1.00 & $0.7(0.53,0.93)$ & $0.8(0.61,1.05)$ & $0.77(0.58,1.02)$ & $0.63(0.47,0.85)$ \\
\hline \multicolumn{7}{|l|}{ WHI $(N=72,425)$} \\
\hline \multicolumn{7}{|l|}{ Non-smoker } \\
\hline Dietary sodium intake ${ }^{a}$ & 2606.6 & $<2288.0$ & $2288.0-2512.8$ & $2512.8-2706.5$ & $2706.5-2955.8$ & $\geq 2955.8$ \\
\hline Cases/person-years & $299 / 591252$ & $47 / 117619$ & $59 / 118170$ & $75 / 117939$ & $50 / 119520$ & $68 / 118004$ \\
\hline Multivariable model $\mathrm{HR}^{\mathrm{b}}$ & $1.06(0.83,1.36)$ & 1.00 & $1.18(0.80,1.74)$ & $1.48(1.02,2.15)$ & $0.96(0.64,1.44)$ & $1.31(0.90,1.90)$ \\
\hline \multicolumn{7}{|l|}{ Smoker } \\
\hline Dietary sodium intake ${ }^{a}$ & 2635.4 & $<2294.5$ & $2294.5-2532.3$ & 2532.3-2739.6 & $2739.6-3008.8$ & $\geq 3008.8$ \\
\hline Cases/person-years & $1332 / 532218$ & $274 / 104588$ & $247 / 106122$ & $275 / 106719$ & $262 / 107372$ & $274 / 107417$ \\
\hline Multivariable model $\mathrm{HR}^{\mathrm{b}}$ & $1.02(0.91,1.15)$ & 1.00 & $0.89(0.74,1.06)$ & $1.01(0.85,1.19)$ & $0.97(0.81,1.15)$ & $1.02(0.86,1.21)$ \\
\hline
\end{tabular}

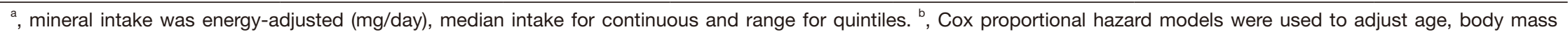
index $\left(\mathrm{kg} / \mathrm{m}^{2}\right)$, energy intake (kcal/day), educational level (3 categories), alcohol consumption (g/day), history of diabetes (yes or no), and family history of cancer (yes or no). 
Table S7 Smoking-status-specific hazard ratios and 95\% confidence intervals of lung cancer based on categories of dietary potassium intake

\begin{tabular}{|c|c|c|c|c|c|c|}
\hline & Continuous & Quintile 1 & Quintile 2 & Quintile 3 & Quintile 4 & Quintile 5 \\
\hline \multicolumn{7}{|l|}{ PLCO (male, N=44,959) } \\
\hline \multicolumn{7}{|l|}{ Non-smoker } \\
\hline Dietary potassium intake ${ }^{a}$ & 3437.7 & $<2897.7$ & 2897.7-3270.6 & $3270.6-3601.0$ & $3601.0-4064.8$ & $\geq 4064.8$ \\
\hline Cases/person-years & $38 / 132602$ & $6 / 26769$ & $9 / 26261$ & $8 / 26410$ & $7 / 26640$ & $8 / 26522$ \\
\hline Multivariable model $\mathrm{HR}^{\mathrm{b}}$ & $1.05(0.67,1.64)$ & 1.00 & $1.35(0.47,3.85)$ & $1.18(0.40,3.47)$ & $1.06(0.35,3.20)$ & $1.35(0.46,3.96)$ \\
\hline \multicolumn{7}{|l|}{ Smoker } \\
\hline Dietary potassium intake ${ }^{a}$ & 3524.1 & $<2959.1$ & $2959.1-3350.0$ & $3350.0-3707.1$ & $3707.1-4190.8$ & $\geq 4190.8$ \\
\hline Cases/person-years & $697 / 211235$ & $146 / 42028$ & $121 / 42262$ & $141 / 42213$ & $151 / 42261$ & $138 / 42471$ \\
\hline Multivariable model $\mathrm{HR}^{\mathrm{b}}$ & $1.05(0.96,1.16)$ & 1.00 & $0.87(0.68,1.12)$ & $1.01(0.79,1.28)$ & $1.09(0.86,1.38)$ & $1.01(0.79,1.29)$ \\
\hline \multicolumn{7}{|l|}{ PLCO (female, N=48,025) } \\
\hline \multicolumn{7}{|l|}{ Non-smoker } \\
\hline Dietary potassium intake ${ }^{a}$ & 2911.6 & $<2439.0$ & $2439.0-2767.7$ & $2767.7-3061.8$ & $3061.8-3442.9$ & $\geq 3442.9$ \\
\hline Cases/person-years & $67 / 226058$ & $13 / 45159$ & $12 / 45148$ & $8 / 45041$ & $16 / 45279$ & $18 / 45431$ \\
\hline Multivariable model $\mathrm{HR}^{\mathrm{b}}$ & $1.08(0.75,1.55)$ & 1.00 & $0.84(0.38,1.87)$ & $0.54(0.22,1.32)$ & $1.06(0.50,2.23)$ & $1.18(0.57,2.43)$ \\
\hline \multicolumn{7}{|l|}{ Smoker } \\
\hline Dietary potassium intake ${ }^{a}$ & 2987.3 & $<2497.0$ & $2497.0-2838.6$ & $2838.6-3145.3$ & $3145.3-3547.2$ & $\geq 3547.2$ \\
\hline Cases/person-years & $476 / 164935$ & $113 / 32702$ & $98 / 32878$ & $80 / 32926$ & $86 / 33252$ & $99 / 33177$ \\
\hline Multivariable model $\mathrm{HR}^{\mathrm{b}}$ & $0.89(0.78,1.02)$ & 1.00 & $0.85(0.64,1.11)$ & $0.68(0.51,0.92)$ & $0.72(0.54,0.96)$ & $0.82(0.63,1.08)$ \\
\hline \multicolumn{7}{|l|}{ WHI $(\mathrm{N}=72,425)$} \\
\hline \multicolumn{7}{|l|}{ Non-smoker } \\
\hline Dietary potassium intake ${ }^{a}$ & 2620.1 & $<2155.4$ & $2155.4-2475.3$ & 2475.3-2768.3 & 2768.3-3141.0 & $\geq 3141.0$ \\
\hline Cases/person-years & 299/591252 & $49 / 109249$ & $61 / 116531$ & $58 / 120013$ & $56 / 122309$ & $75 / 123150$ \\
\hline Multivariable model $\mathrm{HR}^{\mathrm{b}}$ & $1.02(0.85,1.23)$ & 1.00 & $1.04(0.71,1.52)$ & $0.91(0.61,1.34)$ & $0.82(0.55,1.21)$ & $1.05(0.72,1.51)$ \\
\hline \multicolumn{7}{|l|}{ Smoker } \\
\hline Dietary potassium intake ${ }^{a}$ & 2618.2 & $<2153.2$ & 2153.2-2473.5 & $2473.5-2768.1$ & $2768.1-3138.1$ & $\geq 3138.1$ \\
\hline Cases/person-years & $1332 / 532218$ & $317 / 98557$ & $270 / 103957$ & $278 / 108909$ & $243 / 109755$ & $224 / 111040$ \\
\hline Multivariable model $\mathrm{HR}^{\mathrm{b}}$ & $0.77(0.70,0.85)$ & 1.00 & $0.77(0.65,0.90)$ & $0.74(0.63,0.87)$ & $0.63(0.53,0.75)$ & $0.57(0.48,0.68)$ \\
\hline
\end{tabular}

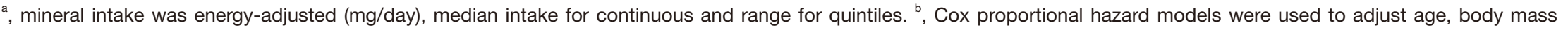
index $\left(\mathrm{kg} / \mathrm{m}^{2}\right)$, energy intake (kcal/day), educational level (3 categories), alcohol consumption (g/day), history of diabetes (yes or no), and family history of cancer (yes or no). 
Table S8 Hazard ratios and 95\% confidence intervals of NSCLC based on categories of dietary mineral intake

\begin{tabular}{|c|c|c|c|c|c|c|}
\hline & Continuous & Quintile 1 & Quintile 2 & Quintile 3 & Quintile 4 & Quintile 5 \\
\hline \multicolumn{7}{|l|}{ Potassium } \\
\hline \multicolumn{7}{|l|}{ WHI (female only) } \\
\hline Dietary intake ${ }^{a}$ & 2620.0 & $<2154.1$ & 2154.1-2474.5 & $2474.5-2768.9$ & 2768.9-3139.7 & $>3139.7$ \\
\hline Cases/person-years & $1258 / 1119323$ & $272 / 207260$ & $248 / 219708$ & $258 / 227841$ & $252 / 231049$ & 228/233465 \\
\hline Multivariable model $\mathrm{HR}^{\mathrm{b}}$ & $0.95(0.87,1.04)$ & 1.00 & $0.90(0.76,1.08)$ & $0.92(0.78,1.10)$ & $0.90(0.75,1.07)$ & $0.82(0.68,0.98)$ \\
\hline$P$ value & 0.296 & & & 0.044 & & \\
\hline \multicolumn{7}{|l|}{ Female in the PLCO } \\
\hline Dietary intake ${ }^{a}$ & 2943.6 & $<2463.5$ & 2463.5-2796.9 & 2796.9-3096.6 & $3096.6-3487.5$ & $>3487.5$ \\
\hline Cases/person-years & $466 / 390602$ & $103 / 77807$ & $91 / 77910$ & $76 / 77886$ & $90 / 78513$ & $106 / 78485$ \\
\hline Multivariable model $\mathrm{HR}^{\mathrm{b}}$ & $0.96(0.84,1.09)$ & 1.00 & $0.90(0.67,1.20)$ & $0.73(0.54,0.98)$ & $0.84(0.63,1.12)$ & $0.92(0.70,1.21)$ \\
\hline$P$ value & 0.504 & & & 0.572 & & \\
\hline \multicolumn{7}{|l|}{ Male in the PLCO } \\
\hline Dietary intake ${ }^{a}$ & 3489.3 & $<2935.4$ & 2935.4-3318.9 & $3318.9-3669.3$ & $3669.3-4141.1$ & $>4141.1$ \\
\hline Cases/person-years & $626 / 343406$ & $129 / 68713$ & $109 / 68395$ & $121 / 68569$ & $138 / 68812$ & $129 / 68917$ \\
\hline Multivariable model $\mathrm{HR}^{\mathrm{b}}$ & $1.06(0.96,1.17)$ & 1.00 & $0.92(0.71,1.19)$ & $1.02(0.79,1.31)$ & $1.12(0.88,1.44)$ & $1.05(0.81,1.35)$ \\
\hline$P$ value & 0.248 & & & 0.380 & & \\
\hline \multicolumn{7}{|l|}{ Female in two cohorts } \\
\hline Dietary intake ${ }^{a}$ & 2750.1 & $<2254.2$ & $2254.2-2598.0$ & 2598.0-2907.1 & 2907.1-3298.1 & $>3298.1$ \\
\hline Cases/person-years & $1724 / 1509925$ & $401 / 313186$ & $360 / 316330$ & $370 / 306196$ & $276 / 296119$ & $317 / 278094$ \\
\hline Multivariable model $\mathrm{HR}^{\mathrm{b}}$ & $0.95(0.88,1.03)$ & 1.00 & $0.94(0.82,1.09)$ & $1.00(0.87,1.16)$ & $0.77(0.66,0.91)$ & $0.91(0.78,1.06)$ \\
\hline$P$ value & 0.201 & & & 0.079 & & \\
\hline \multicolumn{7}{|l|}{ Sodium } \\
\hline \multicolumn{7}{|l|}{ WHI (female only) } \\
\hline Dietary intake ${ }^{a}$ & 2620.1 & $<2291.5$ & $2291.5-2522.3$ & 2522.3-2722.2 & $2722.2-2980.2$ & $>2980.2$ \\
\hline Cases/person-years & $1258 / 1119323$ & $254 / 221225$ & $237 / 223500$ & $264 / 224031$ & $237 / 226100$ & $266 / 224467$ \\
\hline Multivariable model $\mathrm{HR}^{\mathrm{b}}$ & $1.10(0.98,1.23)$ & 1.00 & $1.00(0.84,1.20)$ & $1.16(0.97,1.39)$ & $1.04(0.87,1.25)$ & $1.13(0.95,1.35)$ \\
\hline$P$ value & 0.114 & & & 0.168 & & \\
\hline \multicolumn{7}{|l|}{ Female in the PLCO } \\
\hline Dietary intake ${ }^{a}$ & 2361 & $<2083.7$ & 2083.7-2280.1 & $2280.1-2442.7$ & $2442.7-2656.3$ & $>2656.3$ \\
\hline Cases/person-years & $466 / 390602$ & $116 / 77472$ & $95 / 78008$ & $95 / 78058$ & $83 / 78741$ & $77 / 78322$ \\
\hline Multivariable model $\mathrm{HR}^{\mathrm{b}}$ & $0.82(0.66,1.01)$ & 1.00 & $0.91(0.69,1.21)$ & $0.98(0.74,1.31)$ & $0.83(0.62,1.11)$ & $0.73(0.54,0.98)$ \\
\hline$P$ value & 0.058 & & & 0.03 & & \\
\hline \multicolumn{7}{|l|}{ Male in the PLCO } \\
\hline Dietary intake ${ }^{a}$ & 3108.5 & $<2731.7$ & 2731.7-2996.2 & 2996.2-3228.9 & $3228.9-3551.0$ & $>3551.0$ \\
\hline Cases/person-years & $626 / 343406$ & $128 / 68174$ & $110 / 68399$ & $133 / 68534$ & $132 / 68979$ & $123 / 69321$ \\
\hline Multivariable model $\mathrm{HR}^{\mathrm{b}}$ & $1.22(1.06,1.40)$ & 1.00 & $1.02(0.78,1.33)$ & $1.31(1.01,1.69)$ & $1.32(1.02,1.71)$ & $1.23(0.94,1.61)$ \\
\hline$P$ value & 0.004 & & & 0.044 & & \\
\hline \multicolumn{7}{|l|}{ Female in two cohorts } \\
\hline Dietary intake ${ }^{a}$ & 2507.6 & $<2186.2$ & 2186.2-2409.2 & $2409.2-2610.3$ & $2610.3-2871.3$ & $>2871.3$ \\
\hline Cases/person-years & $1724 / 1509925$ & $328 / 265041$ & $294 / 278409$ & $355 / 300244$ & $366 / 324259$ & $381 / 341972$ \\
\hline Multivariable model $\mathrm{HR}^{\mathrm{b}}$ & $1.02(0.93,1.13)$ & 1.00 & $0.95(0.81,1.11)$ & $1.10(0.94,1.28)$ & $1.06(0.90,1.24)$ & $1.04(0.89,1.21)$ \\
\hline$P$ value & 0.651 & & & 0.590 & & \\
\hline
\end{tabular}

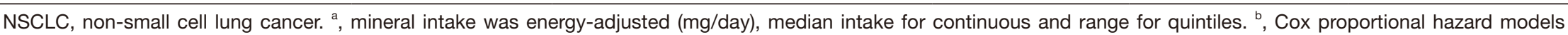

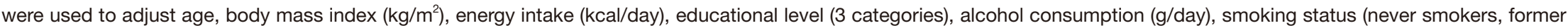

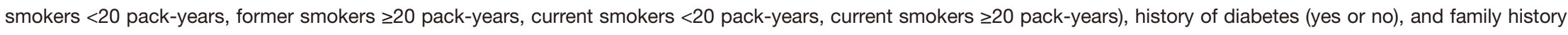
of lung cancer (yes or no) for the PLCO trial or family history of cancer (yes or no) for the WHI cohort. 
Table S9 Hazard ratios and 95\% confidence intervals of SCLC based on categories of dietary mineral intake

\begin{tabular}{|c|c|c|c|c|c|c|}
\hline & Continuous & Quintile 1 & Quintile 2 & Quintile 3 & Quintile 4 & Quintile 5 \\
\hline \multicolumn{7}{|l|}{ Potassium } \\
\hline \multicolumn{7}{|l|}{ WHI (female only) } \\
\hline Dietary intake ${ }^{a}$ & 2620.1 & $<2154.6$ & 2154.6-2474.5 & $2474.5-2769.1$ & 2769.1-3140.5 & $>3140.5$ \\
\hline Cases/person-years & $104 / 1107063$ & $25 / 204969$ & $28 / 217172$ & $22 / 225340$ & $13 / 228607$ & $16 / 230975$ \\
\hline Multivariable model $\mathrm{HR}^{\mathrm{b}}$ & $1.01(0.74,1.38)$ & 1.00 & $1.48(0.85,2.57)$ & $1.29(0.72,2.34)$ & $0.85(0.43,1.69)$ & $1.14(0.60,2.19)$ \\
\hline$P$ value & 0.934 & & & 0.874 & & \\
\hline \multicolumn{7}{|l|}{ Female in the PLCO } \\
\hline Dietary intake ${ }^{a}$ & 2944.1 & $<2464.1$ & 2464.1-2797.8 & 2797.8-3096.9 & $3096.9-3486.9$ & $>3486.9$ \\
\hline Cases/person-years & $77 / 388847$ & $20 / 77436$ & $15 / 77545$ & $11 / 77490$ & 13/78192 & $18 / 78183$ \\
\hline Multivariable model $\mathrm{HR}^{\mathrm{b}}$ & $1.01(0.74,1.37)$ & 1.00 & $0.89(0.45,1.76)$ & $0.67(0.32,1.44)$ & $0.76(0.37,1.56)$ & $0.96(0.50,1.84)$ \\
\hline$P$ value & 0.967 & & & 0.839 & & \\
\hline \multicolumn{7}{|l|}{ Male in the PLCO } \\
\hline Dietary intake ${ }^{a}$ & 3489.2 & $<2936.0$ & 2936.0-3319.1 & $3319.1-3669.2$ & $3669.2-4141.2$ & $>4141.2$ \\
\hline Cases/person-years & $109 / 340959$ & $23 / 68263$ & $19 / 67890$ & $23 / 68001$ & $21 / 68349$ & $23 / 68456$ \\
\hline Multivariable model $\mathrm{HR}^{\mathrm{b}}$ & $1.09(0.87,1.37)$ & 1.00 & $1.04(0.55,1.96)$ & $1.26(0.68,2.32)$ & $1.09(0.58,2.04)$ & $1.11(0.60,2.06)$ \\
\hline$P$ value & 0.474 & & & 0.740 & & \\
\hline \multicolumn{7}{|l|}{ Female in two cohorts } \\
\hline Dietary intake $\mathrm{a}^{\mathrm{a}}$ & 2751.2 & $<2255.2$ & $2255.2-2598.8$ & 2598.8-2908.6 & 2908.6-3299.1 & $>3299.1$ \\
\hline Cases/person-years & $181 / 1495909$ & $49 / 310423$ & $37 / 313390$ & $32 / 303463$ & $26 / 293127$ & $37 / 275507$ \\
\hline Multivariable model $\mathrm{HR}^{\mathrm{b}}$ & $1.02(0.82,1.27)$ & 1.00 & $1.01(0.65,1.56)$ & $0.91(0.57,1.44)$ & $0.76(0.46,1.25)$ & $1.02(0.64,1.61)$ \\
\hline$P$ value & 0.845 & & & 0.916 & & \\
\hline \multicolumn{7}{|l|}{ Sodium } \\
\hline \multicolumn{7}{|l|}{ WHI (female only) } \\
\hline Dietary intake $\mathrm{a}^{\mathrm{a}}$ & 2620.2 & $<2291.7$ & $2291.7-2522.3$ & 2522.3-2722.4 & 2722.4-2980.1 & $>2980.1$ \\
\hline Cases/person-years & $104 / 1107063$ & $24 / 218814$ & $11 / 220929$ & $23 / 221658$ & $21 / 223590$ & $25 / 222071$ \\
\hline Multivariable model $\mathrm{HR}^{\mathrm{b}}$ & $1.23(0.84,1.80)$ & 1.00 & $0.57(0.27,1.17)$ & $1.31(0.72,2.38)$ & $1.22(0.66,2.24)$ & $1.37(0.76,2.46)$ \\
\hline$P$ value & 0.289 & & & 0.101 & & \\
\hline \multicolumn{7}{|l|}{ Female in the PLCO } \\
\hline Dietary intake $e^{a}$ & 2361.8 & $<2084.4$ & $2084.4-2280.8$ & $2280.8-2443.7$ & $2443.7-2656.9$ & $>2656.9$ \\
\hline Cases/person-years & $77 / 388847$ & $27 / 77185$ & $6 / 77711$ & $11 / 77733$ & $17 / 78303$ & $16 / 77915$ \\
\hline Multivariable model $\mathrm{HR}^{\mathrm{b}}$ & $0.90(0.56,1.43)$ & 1.00 & $0.27(0.11,0.67)$ & $0.57(0.27,1.18)$ & $0.80(0.43,1.52)$ & $0.63(0.33,1.20)$ \\
\hline$P$ value & 0.642 & & & 0.437 & & \\
\hline \multicolumn{7}{|l|}{ Male in the PLCO } \\
\hline Dietary intake ${ }^{a}$ & 3108.5 & $<2731.9$ & 2731.9-2996.2 & 2996.2-3229.2 & $3229.2-3551.6$ & $>3551.6$ \\
\hline Cases/person-years & $109 / 340959$ & $28 / 67692$ & $16 / 67906$ & $16 / 68081$ & $27 / 68453$ & $22 / 68828$ \\
\hline Multivariable model $\mathrm{HR}^{\mathrm{b}}$ & $1.03(0.75,1.41)$ & 1.00 & $0.80(0.42,1.52)$ & $0.83(0.43,1.59)$ & $1.31(0.74,2.33)$ & $0.95(0.51,1.75)$ \\
\hline$P$ value & 0.872 & & & 0.729 & & \\
\hline \multicolumn{7}{|l|}{ Female in two cohorts } \\
\hline Dietary intake ${ }^{a}$ & 2507.3 & $<2186.2$ & $2186.2-2408.9$ & 2408.9-2609.9 & $2609.9-2871.0$ & $>2871.0$ \\
\hline Cases/person-years & $181 / 1495909$ & $47 / 262551$ & $24 / 275882$ & $34 / 297246$ & $36 / 321279$ & $40 / 338951$ \\
\hline Multivariable model $\mathrm{HR}^{\mathrm{b}}$ & $1.07(0.80,1.44)$ & 1.00 & $0.64(0.38,1.05)$ & $0.95(0.60,1.51)$ & $1.00(0.63,1.58)$ & $1.11(0.70,1.74)$ \\
\hline$P$ value & 0.652 & & & 0.164 & & \\
\hline
\end{tabular}

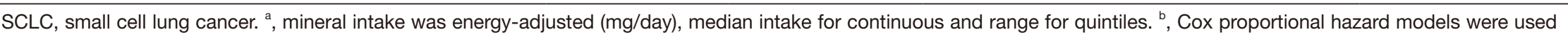

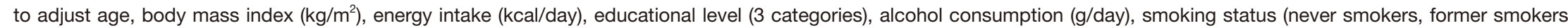

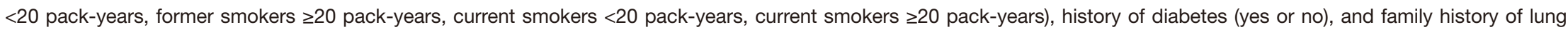
cancer (yes or no) for the PLCO trial or family history of cancer (yes or no) for the WHI cohort. 